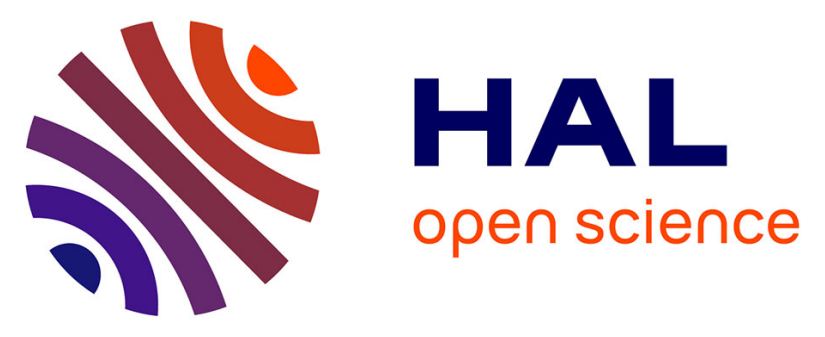

\title{
Nanostructural Evolution of Natural Rubber/Silica Nanoparticle Coagulation from Binary Colloidal Suspensions to Composites: Implications for Tire Materials
}

Gianluca Cattinari, Karine Steenkeste, Sandrine Lévêque-Fort, Clément Cabriel, Ariane Deniset-Besseau, Alexis Canette, Julian Oberdisse, Matthieu Gallopin, Marc Couty, Marie-Pierre Fontaine-Aupart

\section{- To cite this version:}

Gianluca Cattinari, Karine Steenkeste, Sandrine Lévêque-Fort, Clément Cabriel, Ariane DenisetBesseau, et al.. Nanostructural Evolution of Natural Rubber/Silica Nanoparticle Coagulation from Binary Colloidal Suspensions to Composites: Implications for Tire Materials. ACS Applied Nano Materials, 2021, 4 (7), pp.6722-6733. 10.1021/acsanm.1c00725 . hal-03384154

\author{
HAL Id: hal-03384154 \\ https://hal.science/hal-03384154
}

Submitted on 18 Oct 2021

HAL is a multi-disciplinary open access archive for the deposit and dissemination of scientific research documents, whether they are published or not. The documents may come from teaching and research institutions in France or abroad, or from public or private research centers.
L'archive ouverte pluridisciplinaire HAL, est destinée au dépôt et à la diffusion de documents scientifiques de niveau recherche, publiés ou non, émanant des établissements d'enseignement et de recherche français ou étrangers, des laboratoires publics ou privés. 


\section{Nanostructural Evolution of Natural Rubber/Silica}

\section{Nanoparticle Coagulation from Binary Colloidal}

\section{Suspensions to Composites: Implications for Tire}

\section{Materials}

Gianluca Cattinari $^{1 *}$, Karine Steenkeste ${ }^{1}$, Sandrine Lévêque-Fort ${ }^{1}$, Clément Cabriel ${ }^{2}$, Ariane Deniset-Besseau $^{3}$, Alexis Canette ${ }^{4}$, Julian Oberdisse ${ }^{5}$, Matthieu Gallopin ${ }^{6}$, Marc Couty ${ }^{6}$, Marie-Pierre Fontaine-Aupart ${ }^{1}$

${ }^{1}$ Université Paris-Saclay, CNRS, Institut des Sciences Moléculaires d'Orsay, 91405, Orsay, France

${ }^{2}$ Institut Langevin, ESPCI Paris, PSL University, CNRS, 1 rue Jussieu, 75005, Paris, France

${ }^{3}$ Université Paris-Saclay, CNRS, Institut Chimie Physique (LCP), 91405, Orsay, France

${ }^{4}$ Sorbonne Université, CNRS, Institut de Biologie Paris-Seine (IBPS), Service de microscopie électronique (IBPS-SME), F-75005, Paris

${ }^{5}$ Laboratoire Charles Coulomb (L2C), Université de Montpellier, CNRS, F-34095 Montpellier, France

${ }^{6}$ Manufacture Française des Pneumatiques MICHELIN, 23, place des Carmes-Déchaux 63000, Clermont Ferrand, France 
ABSTRACT: The liquid mixing process is an advantageous production method which has recently gained industrial interest for elaborating composites based on natural rubber (NR) and filler nanoparticles (NPs). Understanding how the relevant components such as polymer, fillers, as well as proteins and lipids coming from NR organize along the fabrication process is of importance for modulating material properties. Here, we successfully employed a combination of nano-imaging techniques to unravel the structure and evolution of hetero-aggregates formed by colloidal destabilization of a model NR latex - silica NPs liquid mixing process. First, field emission scanning electron microscopy (FESEM) was used to investigate the structures, from the early stage of contact between the particles until the formation of a composite. Results highlight an interaction in the liquid state between NR globules contained within the latex and silica NPs, hindering coalescence among globules. The latter can be achieved by applying shear in suspension or by solvent evaporation obtaining a dried composite. Atomic force microscopy coupled to infrared spectroscopy (AFM-IR) was employed to probe the in-depth nanoscopic distribution of silica NPs revealing a restricted mobility of the NPs during evaporation. Ultimately, the spatial distribution of proteins and lipids of NR, with respect to silica NPs, was investigated using dual color fluorescence images acquired with direct stochastic optical reconstruction microscopy (dSTORM) in a correlative light electron microscopy (CLEM) approach. The presence of silica NPs is found to influence the distribution of proteins and lipids in the composite; biomolecules form clusters of $\sim 200 \mathrm{~nm}$, which are partially colocalized with silica, highlighting an interaction between them. Our work provides comprehensive structural understanding of a model system undergoing liquid mixing, unlocking the potential of combining high-resolution imaging techniques to elucidate the structure of materials for tire applications. 
KEYWORDS: Nano-imaging; multi detection FESEM; d-STORM; AFM-IR; Natural rubber; silica; coagulation

\section{INTRODUCTION}

Synthetic or Natural Rubber (NR), i.e. crosslinked polymeric systems, need to be reinforced with fillers nanoparticles to achieve necessary strength for most applications ${ }^{1-3}$. The use of silica nanoparticles $\left(\mathrm{SiO}_{2} \mathrm{NPs}\right)$ as filler has become of growing importance, especially in the tire industry ${ }^{4-6}$. It has been found that their introduction into rubber blends has improved the rollingresistance of tires with related benefits such as fuel saving and reduced impact on the environment ${ }^{7,8}$. The complex three-dimensional arrangement of $\mathrm{SiO}_{2} \mathrm{NPs}_{\mathrm{s}}$ with their large distribution of length scales in case of industrial filler particles, depends on formulation of additives and the incorporation methods, and presumably determines material reinforcement ${ }^{9,10}$. Various strategies have been developed to incorporate silica fillers in NR like melt mixing and solgel techniques ${ }^{11}$. Among those, the "liquid route" is a both industrially and environmentally promising approach. It relies on the coagulation of a colloidal mixture of NR latex with an aqueous suspension of $\mathrm{SiO}_{2} \mathrm{NPs}$ that is further dried to obtain a masterbatch material. The masterbatch is thermo-mechanically mixed with additives such as synthetic polymers and vulcanization agents to achieve a composite material of relevance for the tire industry. Such a strategy takes advantage of the core-shell structure of NR globules contained within the latex, with the core constituted of polyisoprene and the shell composed of proteins and lipids ${ }^{12}$, biocomponents partially linked with the polymer core of the globules ${ }^{13}$. In terms of processing, different options are available: the colloidal mixture can be directly dried to form a continuous polymer film with embedded fillers ${ }^{14}$ or it can be coagulated by chemical and/or mechanical actions ${ }^{15-17}$, before drying. For industrial 
use, coagulation methods are preferred since they speed up composite formation. An advantageous method for obtaining NR-SiO 2 composite at industrial scale starting from colloidal suspensions relies on the use of divalent metallic cations to induce coagulation between NR latex and pristine silica $^{18}$. Obviously, the physical chemistry of the silica-polymer interface remains unmodified during the coagulation approach, unless specific surface treatment is introduced, as e.g. with coating or coupling agents as usually done with synthetic rubber. However, such treatments are out of the scope of the present study. A previous research by Chan et al. ${ }^{19}$ explored the physicochemical parameters required to achieve $\mathrm{NR}-\mathrm{SiO}_{2} \mathrm{NPs}$ interaction under aqueous conditions by varying properties of the medium (ionic strength, ion valence) as well as the size and surface chemistry of the fillers. In terms of aggregation kinetics, the authors reported that even though monovalent ions can be used to trigger coagulation, the rate of hetero-aggregate formation is faster when using $\mathrm{Mg}^{2+}$ ions. Furthermore, the recent work of Sattar et al. ${ }^{20}$ provided insights into molecular scale interactions present in the NR - $\mathrm{SiO}_{2} \mathrm{NPs}$ composite obtained through coagulation also induced by $\mathrm{Mg}^{2+}$ ions. However, the aforementioned studies did not benefit from images unravelling structural details. Indeed, the nanoscale visualization of the hetero-aggregate, as well as its structural evolution during coagulation and drying have never been achieved. To do so, the use of highly resolved imaging techniques investigating model systems mimicking processes occurring during the liquid route are necessary.

Techniques such as Small-angle neutron and X-ray scattering (SANS and SAXS) have been widely used for morphological studies of polymeric systems ${ }^{9,10,21}$, to investigate the microstructure of uncross-linked $\mathrm{NR}^{22}$, and only very rarely to coagulated latex systems ${ }^{23}$. However, these techniques often have complicated data analysis and require stochastic inversion techniques ${ }^{24}$, to compare with direct visual microscopy images showing silica particles localization. The originality 
of our work stands in the use of a set of multimodal nano-imaging techniques for structural characterization of NR-fillers systems, giving access to nanoscale details in both hydrated and dehydrated conditions. In particular, we employed field emission scanning electron microscopy (FESEM) with a multi detection mode of secondary and backscattering electrons to investigate the overall structural evolution of the sample, from the early stage of contact between NR globules and $\mathrm{SiO}_{2} \mathrm{NPs}$ in the liquid state, until the formation of a dehydrated composite. Additionally, FESEM was supported by atomic force microscopy coupled to infrared spectroscopy (AFM-IR) to reveal the distribution of $\mathrm{SiO}_{2} \mathrm{NPs}$ in the rubber matrix, giving access to greater surface depth analysis. The structural evolution and the fillers distribution were also explored after application of mechanical shear-stress using a novel rheo-optical device ${ }^{25}$ to study the role of shear in the transition from hetero-aggregate to a composite. Ultimately, direct stochastic optical reconstruction microscopy (d-STORM) was used to investigate the spatial distribution of proteins and lipids of NR in both the liquid state and composite material, and with respect to $\mathrm{SiO}_{2} \mathrm{NPs}$. In this context, Correlative Light Electron Microscopy (CLEM) combining d-STORM acquisitions with subsequent FESEM observations was achieved recovering the same position of the sample.

Overall, our work reports novel experimental findings exploring nanoscale structural aspects of $\mathrm{NR}$ and $\mathrm{SiO}_{2} \mathrm{NPs}$ involved in the liquid route used for the manufacturing of composite for tire applications.

\section{MATERIALS AND METHODS}

\subsection{Sample Preparation}

High ammonia NR latex concentrate ( $\sim 60 \mathrm{wt} \%$, HA latex) (Michelin, Clermont Ferrand, France) was used for all the experiments. It was obtained by centrifugation of field NR latex containing 
$0.7 \mathrm{wt} \%$ ammonia to eliminate free components and non rubber particles as well as to preserve the colloidal structure of NR globules. The latex was diluted to $0.075 \mathrm{wt} \%$ rubber content using distilled water and mixed with $100 \mathrm{~nm}$ diameter plain $\mathrm{SiO}_{2} \mathrm{NPs}$ (Kisker Biotech, Steinfurt, Germany) to obtain a binary colloidal suspension. Dynamic Light Scattering method (DLS) was used to control the size distribution of both components prior mixing (Figure S1). NR latex corresponded to a bimodal distribution of particles with $\sim 90 \%$ of globules belonging to small rubber particles (SRPs) (size $<500 \mathrm{~nm}$ ) and $\sim 10 \%$ belonging to large rubber particles (LRPs) (size $>500$ $\mathrm{nm}$ ), in agreement with previous results ${ }^{26}$. Unless otherwise mentioned, the experiments were conducted in an aqueous medium composed of magnesium sulfate $0.025 \mathrm{M}$ (Sigma-Aldrich) corresponding to $100 \mathrm{mM}$ ionic strength and adjusted at $\mathrm{pH}$ of $\sim 6.5$, a pre-requisite to induce a phase-separation and formation of a NR- $\mathrm{SiO}_{2} \mathrm{NPs}$ hetero-aggregate as previously reported. For imaging experiments, $100 \mu \mathrm{L}$ of the binary colloidal suspension was deposited on a rounded glass coverslip (thickness of $170 \mu \mathrm{m}$, MENZEL-GLASER), resulting in a casted drop with a spherical cap shape (drop diameter $\sim 1 \mathrm{~cm}$ ). Some experiments were conducted in a humidity-controlled chamber, limiting the evaporation of the solvent (Figure 1a). In other experiments, the solvent was let to evaporate to observe structural evolution (Figure 1b). In both cases, a phase-separation was macroscopically visible at $\mathrm{t}=1 \mathrm{~h}$, with the formation of a floating object corresponding to the heteroaggregate. In case of solvent evaporation, at $\mathrm{t}=4 \mathrm{~h}$, the heteroaggregate adhered on the glass surface, and after complete evaporation of the solvent $(t=24 \mathrm{~h})$ the material is referred to as composite. 
(a)
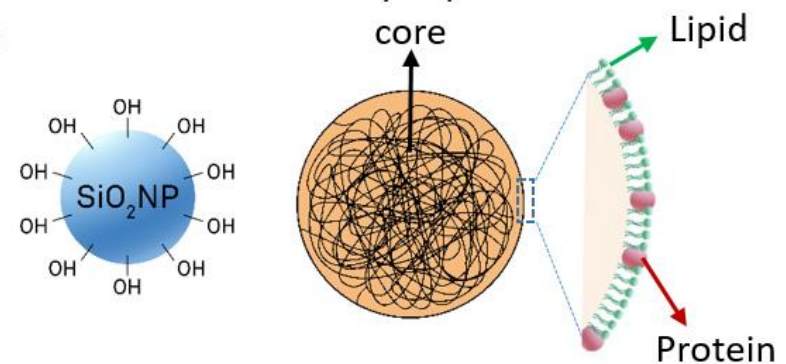

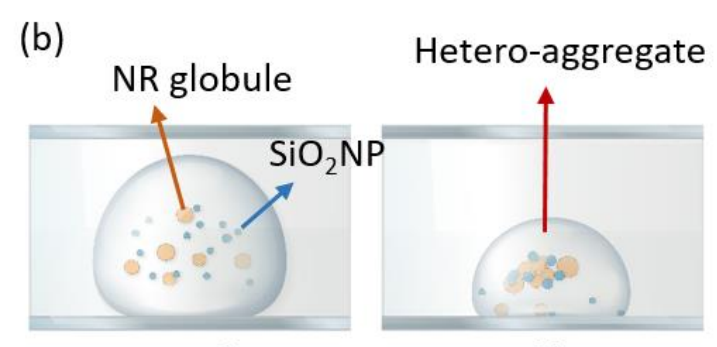

$t=0$ $t>1 h$

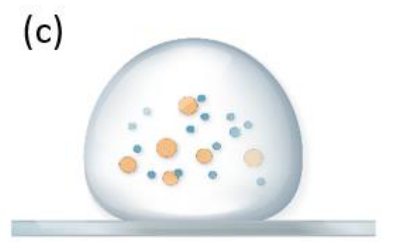

$t=0$

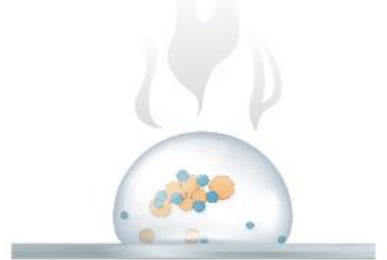

$t=1-4 h$
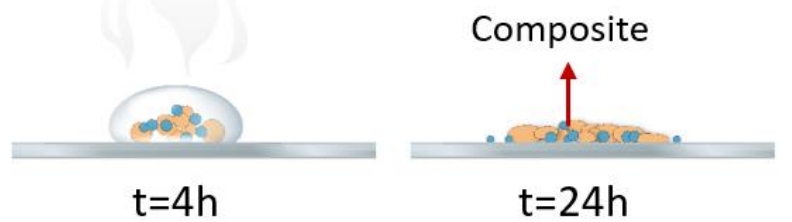

Figure 1. Schematic illustration of the main components and deposition protocol on a coverslip for imaging experiments. (a) Surface chemistry of $\mathrm{SiO}_{2} \mathrm{NPs}$ and typical core-shell structure of NR globule (b) Sample placed in a humidity-controlled chamber limiting the evaporation of the solvent. (c) Sample exposed to the open air along solvent evaporation.

\subsection{Application of controlled shear-stress}

The sample preparation and description of the shearing module used in these experiments were described in details elsewhere ${ }^{27}$. Briefly, the $\mathrm{SiO}_{2} \mathrm{NPs}$ binary colloidal suspension was placed between two microscopy coverslips (with a controlled gap width of $500 \mu \mathrm{m}$ ) well suited for the application of controlled shear. This was obtained using a commercial device called RheOptiCAD (CAD instrument). It consisted in 10 cycles of oscillations during a total of $10 \mathrm{~min}$. Each oscillation corresponds to the displacement of the upper plate of $1 \mathrm{~mm}(500 \mu \mathrm{m}$ on either side from a central position) at a frequency of $10 \mathrm{~Hz}$ during 60 s. It was verified on a sample of only diluted NR latex 
that the shearing conditions did not alter the NR globular form (Figure S2). This shearing device was designed to fit on an inverted microscope (Axiovert, ZEISS) allowing for the acquisition of transmission images of the sample during shear.

\subsection{FESEM}

FESEM using both topological contrast by secondary electrons (SE) imaging and chemical contrast by backscattered electron (BSE) imaging was performed on deposited specimen samples which were chemically fixed using osmium vapors ${ }^{\mathbf{2 8 , 2 9}}$. Osmium is routinely used as fixative agent in solution. However, the originality of our approach relies on (i) its use in the vapor form which prevents the immersion of the specimen in a liquid solution containing the fixative agent, (ii) its applicability in the presence or absence of solvent, and (iii) the specific affinity of osmium tetroxide for NR: Osmium tetroxide interacts directly with carbon-carbon double bonds in unsaturated rubber phases. This gives the possibility to exploit BSE imaging; a method based on chemical contrast allowing the distinction between $\mathrm{NR}$ and $\mathrm{SiO}_{2} \mathrm{NPs}$ : the latter appear dark in comparison to NR globules that are bright (Figure 2b). The chemical fixation protocol was optimized in order to be applied regardless of the amount of solvent still present in the sample. It consists in the deposition of $50 \mu \mathrm{L}$ drops of osmium tetroxide (EMS, USA) solution ( $1 \%$ in water, prepared extemporaneously) around the cover slip of the sample, in a hermetic box protected from light. In this condition, vapors of osmium tetroxide are created inside the box, fixing the structure of the sample. After 30 minutes, the fixation was considered complete and the samples were gently rinsed with ultrapure water to remove the excess of dry salt on the specimen and mounted on 25.4 mm aluminum pin stubs (Micro to Nano, the Netherlands) with double sided sticky and conductive tabs (EMS, USA). Samples were left on the stubs until completely dry in a vacuum desiccator. Afterwards, samples were coated with a $10 \mathrm{~nm}$ carbon layer by double thread evaporation in high 
vacuum $\left(10^{-5} \mathrm{mbar}\right)$ with an ACE600 device (Leica, Germany). Observations were performed in high vacuum $\left(10^{-6} \mathrm{mbar}\right.$ in the observation chamber) with a FESEM Gemini500 (Zeiss, Germany) driven by SmartSEM (version 6.3) operating at $2 \mathrm{kV}$, with high current mode, a $20 \mu \mathrm{m}$ aperture and approximatively $2 \mathrm{~mm}$ working distance. The SE signal was collected with the corresponding SE in lens detector. The BSE signal was collected with the energy selective in column detector using filtering grid (>400 V) to filter out the SE signal. Images were acquired with a $1024 \times 768$ resolution, with a dwell time of $6.4 \mu$ s and a line averaging of 25. Both SE and BSE signals are surface selective; the SE images are produced at the extreme surface (depth of few nanometers) while the BSE images are capable of providing information arising from a depth of few tens of nanometers ${ }^{30}$. For each sample, at least two different zones were imaged using a range of different magnification power.

\subsection{FESEM-Image treatment for quantitative analysis}

The minimum average distance between centroids of nearest NR globules was estimated from the FESEM images of the NR- $\mathrm{SiO}_{2} \mathrm{NPs}$ hetero-aggregate formed at $\mathrm{t}=1 \mathrm{~h}$. For this calculation, the Nearest Neighbor Distance calculation (NND) plugin of ImageJ was used.

SRPs and LRPs were counted in the BSE images recorded from $\mathrm{t}=1 \mathrm{~h}$ to $\mathrm{t}=4 \mathrm{~h}$. To do so, a nonlocal means filter was first applied to subtract the noise from the BSE images. Subsequently, the MorphoLibJ Plugin (ImageJ) was employed on the binary image with the application of watershed segmentation to detect the max Feret diameter of NR particles. This is often used in microscopy measurements for the size analysis of non-spherical particles, and it refers to the longest direction of the globule ${ }^{31}$. A threshold was set at $500 \mathrm{~nm}$ to discriminate the NR particles: they were considered as SRPs below this threshold, while above they were considered as LRPs. The counting was performed in three different image planes for each condition at 10000x magnification. 


\subsection{Fourier Transformed Infrared (FTIR) -Attenuated Total Reflection (ATR) analysis}

The FTIR spectra of $\mathrm{SiO}_{2}$ NPs and NR were acquired using a Bruker Vertex 70 FTIR spectrometer equipped with an ATR accessory (PIKE MIRacle crystal plate diamond ZnSe) and a mercury cadmium telluride (MCT) detector cooled down by liquid nitrogen. For spectra acquisition, HA latex $60 \mathrm{wt} \%$ or the purchased Si suspension at $5 \mathrm{wt} \%$ were dehydrated and subsequently deposited directly on the ATR-crystal. Each FTIR spectrum corresponds to an accumulation of 100 scans

from 4000 to $600 \mathrm{~cm}^{-1}$ and with a spectral resolution of $4 \mathrm{~cm}^{-1}$. The background was recorded (average of 100 scans) on the ATR unit without any substrate pressed against the crystal.

\subsection{AFM-IR}

AFM-IR is a hybrid technique that combines the spatial resolution of atomic force microscopy (AFM) with the chemical analysis capability of infrared (IR) spectroscopy ${ }^{32,33}$. The method was described in details elsewhere. The instrument used in this study is a NanoIR2 (Anasys Instrument, Bruker nano Surfaces, California, US) combining an AFM set-up with an IR pulsed tunable laser covering the mid-IR region between $1900 \mathrm{~cm}^{-1}$ and $900 \mathrm{~cm}^{-1}$ (QLC beam, MIRcat-QT, DAYLIGHT solutions; peak powers up to $1 \mathrm{~W}$; average powers up to $0.5 \mathrm{~W}$, wavelength repeatability $<0.1 \mathrm{~cm}^{-1}$ and a tunable repetition rate of $1-2000 \mathrm{kHz}$ ). The samples were deposited on $\mathrm{CaF}_{2}$ coverslips (Crystal $\mathrm{GmbH}$, Berlin). The system is used in tapping AFM-IR mode ${ }^{33}$. Simultaneous acquisition of topographic images and IR maps at a specific wavenumber are acquired by means of a Au-coated silicon probe (scan rate $0.2 \mathrm{~Hz}$, driving strength $16 \%$, Power 5.77\%, tapping AFM-IR cantilever, Anasys Instruments - spring constant 1-3 nN.m ${ }^{-1}$ ). In tapping mode, the lever is forced to oscillate constantly at a given amplitude and frequency. To perform AFM-IR measurements in this mode, it is therefore essential to detect the oscillation generated by 
the photo-thermal expansion, whereas the cantilever is already oscillating. Here is the strategy: the oscillation frequency of the tapping cantilever is mixed with the photothermal expansion frequency of the object. While the cantilever is driven at a certain frequency for the tap-ping mode (here 1430 $\mathrm{kHz}$ ), the frequency of the laser repetition rate is chosen so that the difference of these two frequencies corresponds to the eigenmode of the cantilever (here around $230 \mathrm{kHZ}$, second mode). The nonlinear interaction produced is therefore directly related to the photo-thermal expansion and will contain all the information related to the IR absorption of the object. A major interest of the IR mapping is that is capable of providing information arising from a depth $>1 \mu \mathrm{m}$, while classic topography images are surface selective as FESEM. Topography and IR maps were treated using MountainsMap software, while local IR spectra were filtered using a Stavitsky-Golay algorithm.

\section{7 d-STORM}

d-STORM has mostly seen applications in the life sciences, but it has recently gained interest in the field of materials ${ }^{34,35}$. The technique relies on the reconstruction of a nanoscale image after recording the stochastic pinpointing of fluorophores that undergo an on-off switching mechanism, also known as blinking ${ }^{36}$. To achieve such temporal signal separation, addition of a chemical imaging buffer to the sample is necessary. The one used herein contained: PBS, $\beta$ mercaptoethylamine and an oxygen scavenger enzymatic system composed of glucose oxidase and catalase (Smart kit, Abbelight, Paris, France). Such buffer performs better in a poor oxygen environment. Thus, the samples were further sealed using Twinsil ${ }^{\circledR}$ paste. To allow the proteins and lipids localization, the biomolecules were fluorescently labelled in liquid suspension with Cy5NHS $(100 \mu \mathrm{M}$, incubation time $1 \mathrm{~h})$ and Dil (25 $\mu \mathrm{M}$, incubation time 10 minutes) respectively. In case of detection of $\mathrm{SiO}_{2} \mathrm{NPs}$ by d-STORM measurements, fluorescent $\mathrm{SiO}_{2} \mathrm{NPs}$ (Kisker Biotech, 
Steinfurt, Germany) were mixed with NR globules. When in presence of fluorescent $\mathrm{SiO}_{2} \mathrm{NPs}$, Dil was replaced by DID as lipid probe to prevent any spectral interference between the probes (Figure S3). Moreover, we controlled that neither Cy5-NHS, nor Dil and DID have interactions with the fluorophore marking $\mathrm{SiO}_{2}$ NPs: no change in the silica emission spectra was observed (Figure S4). Fluorescence images were acquired using a Nikon Eclipse Ti-E microscope equipped with two laser lines. A $532 \mathrm{~nm}$ (Verdi G5, 5W, Coherent) was used to excite the fluorescence of both Dil and fluorescent $\mathrm{SiO}_{2} \mathrm{NPs}$ fillers, while a $637 \mathrm{~nm}$ (Obis 637LX, 140mW, Coherent) line was employed to excite Cy5-NHS as well as DID. Firstly, we used a weak laser power to illuminate the sample and record a conventional diffraction-limited epifluorescence image. Afterwards, the laser power intensities were increased to induce the stochastic photo-switching of the fluorophores. Unless otherwise mentioned, highly-inclined and laminated optical sheets (Hilo) ${ }^{37}$ was used as excitation mode. In this configuration, the incident laser beam is highly inclined by a large refraction and is laminated as a thin optical sheet at the specimen site allowing image acquisition through a depth of several micrometers. The laser light was focused through a high numerical aperture and magnification objective (APO TIRF x100 1.49NA, Nikon), and images were acquired using a complementary metal oxide semiconductor camera (CMOS) with $50 \mathrm{~ms}$ exposure time. Appropriate band pass filters were placed in front of the camera to separate the emission signals of the different fluorophores. A single d-STORM image is generated by the accumulation $\sim 6000$ fluorescence images containing sparsely distributed emitters. The images were acquired and processed using NEO (Abbelight, Paris, France), a commercial software allowing live image reconstruction as well as treatment and drift corrections. With this software, images were processed removing the pixel per pixel temporal median in order to get rid of background noise. 
A Gaussian fit was then used to localize the center of each emitting molecule. The potential drift between sequential acquisitions was also corrected using a cross correlation algorithm.

\subsection{Correlative Light Electron Microscopy (CLEM)}

CLEM was performed combining d-STORM with FESEM measurements. The re-location of the same area of the sample by both methods has been achieved through the use of high wall $35 \mathrm{~mm}$ $\mu$-dishes with a patterned glass bottom coverslips with $170 \mu \mathrm{m}$ thickness and composed of 4 x 100 numbered micro-squares of $50 \mu \mathrm{m}\left(1.5 \mathrm{H}\right.$, Ibidi GmbH) (Figure S5). Fluorescent $\mathrm{SiO}_{2} \mathrm{NPs}_{\text {s particles }}$ were used as bi-functional probe visible by both methods. Due to strong quenching of the fluorescence signal after fixation with vapors of osmium tetroxide ${ }^{38}$, d-STORM acquisitions using Hilo illumination were performed prior to FESEM measurements. Between the two different acquisitions, the d-STORM imaging buffer was carefully washed off, and the glass bottom coverslip was gently removed using tweezers in order to insert the sample in the FESEM chamber.

\subsection{Correlation and cluster analysis}

Fluorescence images have first been analyzed looking for the presence of proteins and lipids clusters using density based spatial clustering of application with noise (DBSCAN) ${ }^{39}$. The DBSCAN algorithm looks for clusters by analyzing the number of localizations within a circle defined by its radius $(\varepsilon)$ and its center $(p)$. If the area of the circle contains more than a minimum number of points (MinPts), a new cluster with $p$ as a core object is created. If a localization does not have MinPts within $\varepsilon$, this point is defined as a border point of the cluster. The choice of $\varepsilon$ and MinPts is operator-dependent. We chose $\varepsilon=50 \mathrm{~nm}$ and MinPts $=50$ as input parameters in order to detect clusters that would allow high density areas of proteins and lipids in a circle having diameter of $100 \mathrm{~nm}$. This method has been applied on two different region of interest (ROI) of the acquired 
d-STORM images, and for each condition. Additionally, a 2D coordinate-based correlation analysis was applied using an in-house code. The code allows to define a typical cluster size with an auto-correlation analysis using lipids and proteins localization coordinates. Similarly to the pair correlation function of liquid state theory ${ }^{40}$, the code calculates the probability of encountering a colored pixel (of the same color, yielding auto-correlation) in a circular shell as a function of the shell radius around a given colored pixel. This probability is then averaged over all colored pixels taken as center, and normed with respect to the average density. Subsequently, cross-correlation was also examined to quantify proteins and lipids colocalization with $\mathrm{SiO}_{2} \mathrm{NPs}$ applying the same code to two different colors. In both cases, results are shown in terms of a radial distribution function $g(r)$ quantifying the possibility of finding a localization at a distance $r$ away from a reference point. Both auto and cross-correlation analysis has been run on two different ROI for three distinct samples to test the reproducibility of the out coming results. Intensity values have not been taken into account for the analysis because they depend on the emission time of single fluorophores undergoing stochastic activation.

\section{RESULTS AND DISCUSSION}

\subsection{NR- $\mathrm{SiO}_{2} \mathrm{NPs}$ hetero-aggregate structure in the liquid state}

FESEM was first used to characterize the structure of the $\mathrm{NR}-\mathrm{SiO}_{2} \mathrm{NPs}$ hetero-aggregate formed from phase-separation of the binary colloidal suspension in the humidity-controlled chamber (Figure 2). From the SE image, it is possible to distinguish LRPs (size $>500 \mathrm{~nm}$ ) (see Materials and Methods) surrounded by particles of smaller size. However, it is difficult to distinguish between SRPs (size $<500 \mathrm{~nm}$ ) and $\mathrm{SiO}_{2} \mathrm{NPs}$, due to their similar size and form (Figure 2a). 
Therefore, BSE images have been acquired simultaneously on the same area, providing the necessary information to distinguish the components (Figure $2 b$ ). The structure of the formed hetero-aggregate highlights NR particles regularly dispersed as single globules maintaining their spherical structure, and surrounded by $\mathrm{SiO}_{2} \mathrm{NPs}$, which fill the void between them. The determination of the minimal average distance between centroids of nearest NR globules (as described in the experimental section) resulted in a value of $\sim 250 \mathrm{~nm}$, confirming that at least one silica nanoparticle is found intercalated between two NR globules. This indicates an attractive interactions between NR globules and $\mathrm{SiO}_{2} \mathrm{NPs}$, inducing a homogeneous distribution of the filler particles around the NR globules. As shown in previous work, this interaction is triggered by the presence of divalent ions able to screen the electrostatic double layer, while acting as a molecular bridge between the negatively charged surfaces of both $\mathrm{SiO}_{2} \mathrm{NPs}(-12.2 \mathrm{mV}, \mathrm{pH} \sim 6.5)$ and proteins and lipids present on the NR biomembrane $(-28.8 \mathrm{mV}, \mathrm{pH} \sim 6.5)^{19,20}$. Remarkably, as long as the solvent is maintained in the system, the reported hetero-aggregated structure does not evolve with time. This means that the interaction between $\mathrm{NR}$ and $\mathrm{SiO}_{2} \mathrm{NPs}$ in the liquid state does not alter the colloidal structure of the NR globules but rather stabilizes it, as it happens in Pickering emulsions $^{41}$. By contrast, FESEM images acquired on an equivalent system composed of only NR latex show no clear globular form of NR, but the presence of a NR film formed by coalescence between NR globules (Figure 2c and d). In this case, we can reasonably hypothesize that the observed coalescence between the NR globules is a consequence of the presence of $\mathrm{Mg}^{2+}$ ions which allows to NR globules to come into closer contact. This results in the ability of the polyisoprene chains confined in the inner part of the NR globules to diffuse toward the outside by polymer interdiffusion and interact with other chains through hydrophobic interactions. The discrepancy between the two reported cases proved that the localization of $\mathrm{SiO}_{2} \mathrm{NPs}$ completely 
surrounding the NR globules is a factor that helps in delaying the coalescence between them, so that they maintain their original form as long as evaporation is limited.
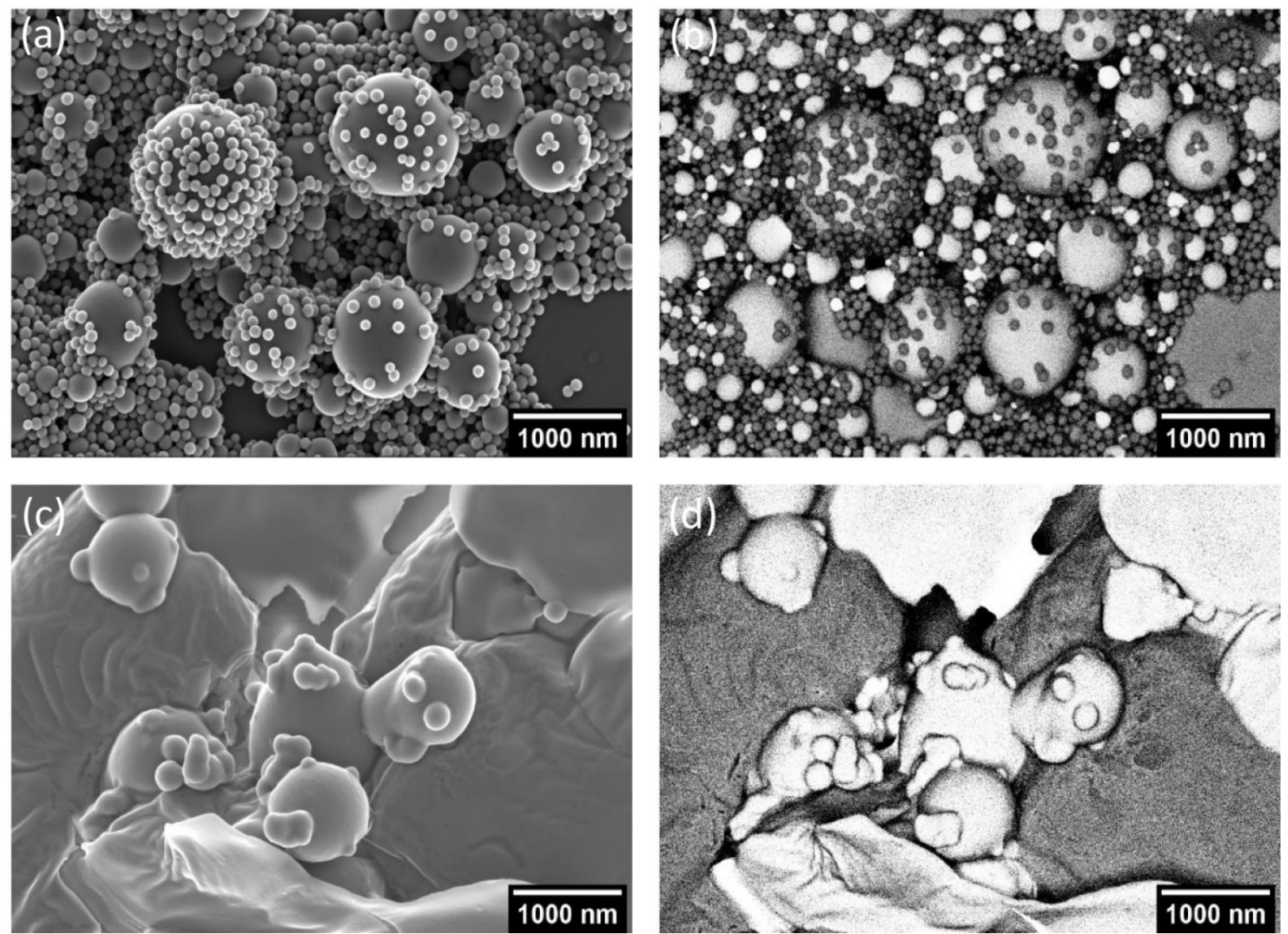

Figure 2. FESEM micrographs of $\mathrm{NR}-\mathrm{SiO}_{2} \mathrm{NPs}$ hetero-aggregate and comparison with the structure obtained for the equivalent system composed of only NR latex. Samples were kept for $4 \mathrm{~h}$ in a humiditycontrolled chamber, limiting evaporation of the solvent prior to fixation. (a) SE and (b) BSE images of the NR-SiO 2 NPs aggregate (magnification: 20000x) showing no signs of coalescence between particles. (c) SE and (d) BSE images of the structure obtained for a system composed of only NR latex, showing large zones of coalescence between NR globules (magnification 20000x).

We further investigated the impact of the aformentioned NR-SiO $2 \mathrm{NPs}$ interaction on the architecture of the biomembrane components. Dual color d-STORM images using fluorescently 
labelled $\mathrm{SiO}_{2} \mathrm{NPs}$ and alternatively proteins or lipids of NR were performed at an early stage of mixing (Figure 3). We highlighted the presence of $\mathrm{SiO}_{2} \mathrm{NPs}$ in contact with the surface of the NR globules, as previously reported by FESEM. Proteins and lipids appear quite homogeneously distributed all around the surface of the globule (Figure $3 \mathrm{a}$ and $\mathrm{b}$ ), as observed in the absence of $\mathrm{SiO}_{2} \mathrm{NPs}$ (Figure $3 \mathrm{c}$ and d). Only some segregated, randomly interdispersed domains can be observed, in particular for proteins, in agreement with previous immunogold studies by TEM microscopy ${ }^{42}$.
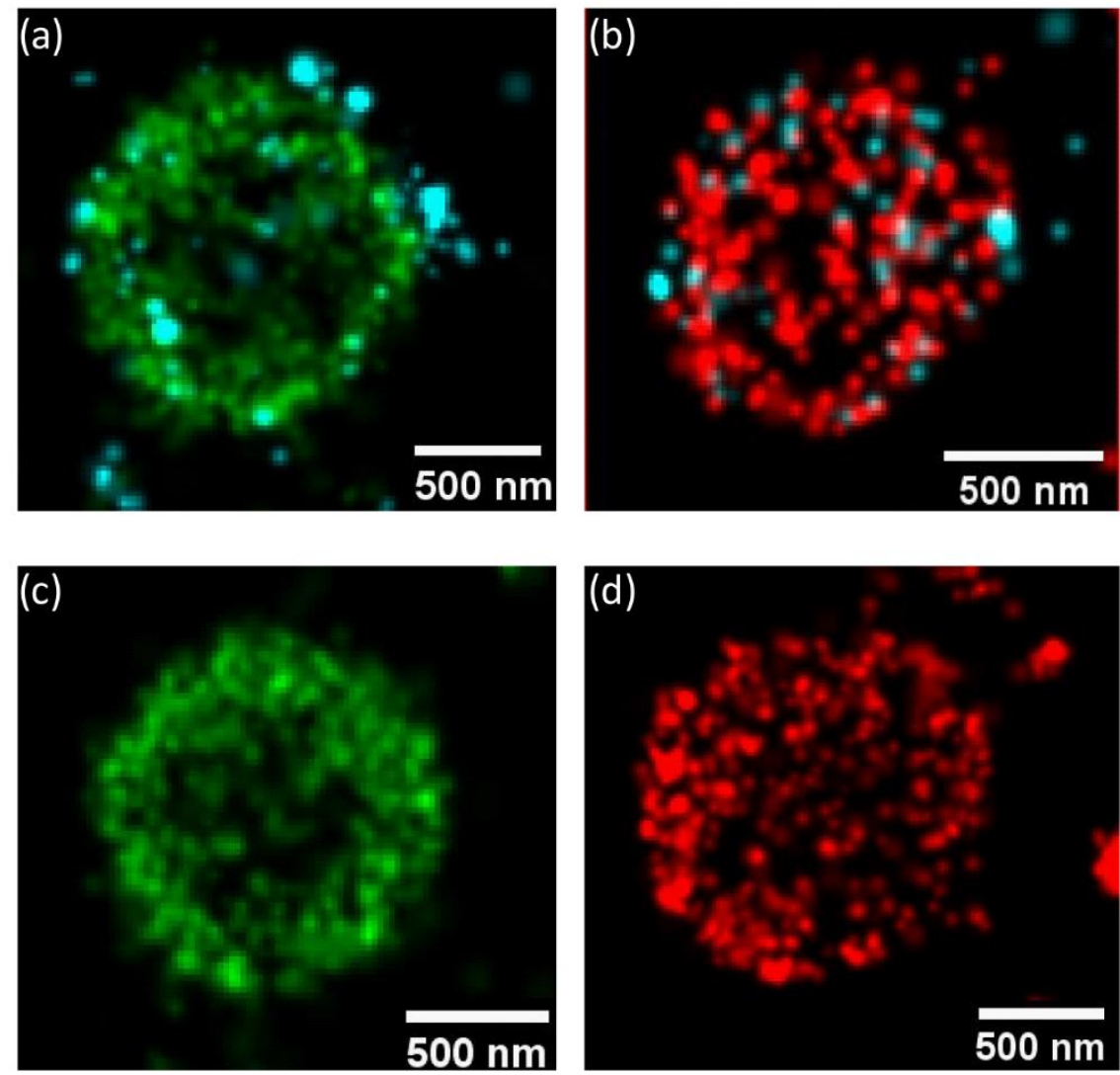

Figure 3. d-STORM micrographs on a NR globule in presence and absence of $\mathrm{SiO}_{2} \mathrm{NPs}$ surrounding their surface. Images have been taken in presence of $\mathrm{Mg}^{2+}$ ions (ionic strength $=0.1$ $\mathrm{M}$ ), using Hilo excitation. (a) Dual color image labelling lipids (green) and $\mathrm{SiO}_{2} \mathrm{NPs}$ (cyan). (b) Dual color image labelling proteins (red) and $\mathrm{SiO}_{2} \mathrm{NPs}$ (cyan). (c) Lipids and (d) proteins 
distribution on a single $\mathrm{NR}$ globule without $\mathrm{SiO}_{2} \mathrm{NPs}$. Note that the quantity of $\mathrm{SiO}_{2} \mathrm{NPs}$ interacting with the NR globules in (a) and (b) is comparable, in spite of the visual impression caused by the color code.

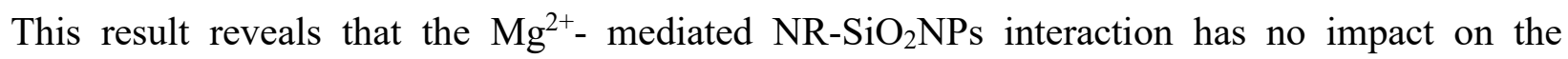
architecture of the NR biomembrane. Hence, without a modification of the proteins and lipids arrangement, the polyisoprene chains confined within the globules are not exposed to the surrounding environment and hydrophobic interactions between polymer chains of different NR

globules are prevented, so that coalescence between them is hindered. In essence, the absence of direct contact between NR globules together with the unmodified arrangement of proteins and lipids following their $\mathrm{Mg}^{2+}$ - mediated interaction with $\mathrm{SiO}_{2} \mathrm{NPs}$ are conditions that oppose coalescence. This lack of globules coalescence in the liquid state presents one of the main differences with NR-carbon black systems, obtained with a similar protocol. For the latter, it was recently reported that when $\mathrm{CB}$ aggregates are in contact with NR globules, coalescence of the latter was promoted ${ }^{27}$.

\subsection{NR-SiO ${ }_{2} \mathrm{NPs}$ hetero-aggregates: Structural evolution during drying and shearing}

We further imaged for the first time the $\mathrm{NR}-\mathrm{SiO}_{2} \mathrm{NPs}$ hetero-aggregate structural evolution towards a solid composite, obtained by solvent evaporation. For this purpose, FESEM images were performed on samples where evaporation was allowed and the structure of the hetero-aggregate was fixed at different times, from $\mathrm{t}=1 \mathrm{~h}$ to $\mathrm{t}=24 \mathrm{~h}$ (Figure $1 \mathrm{~b}$ ). At $\mathrm{t}=1 \mathrm{~h}$ the NR globules still maintain their original colloidal structure while being surrounded by $\mathrm{SiO}_{2} \mathrm{NPs}$ (Figure S6). However, along with the solvent evaporation, structural differences can be noticed. At $t=2 \mathrm{~h}$ particle boundaries are still visible but NR globules begin to deform, partly covering the 
surrounding $\mathrm{SiO}_{2} \mathrm{NPs}$ (Figure 4a). Further with the evaporation, the sample becomes structurally heterogeneous, with regions in which the spherical form of NR globules is still preserved as well as domains characterized by no contour of the particles due to coalescence between the globules (Figure $4 \mathrm{~b}$ and $\mathrm{c}$ ). This last region is the result of a film formation mechanism of NR latex, where coalescence between the NR globules and inter-globular chain diffusion occurs.
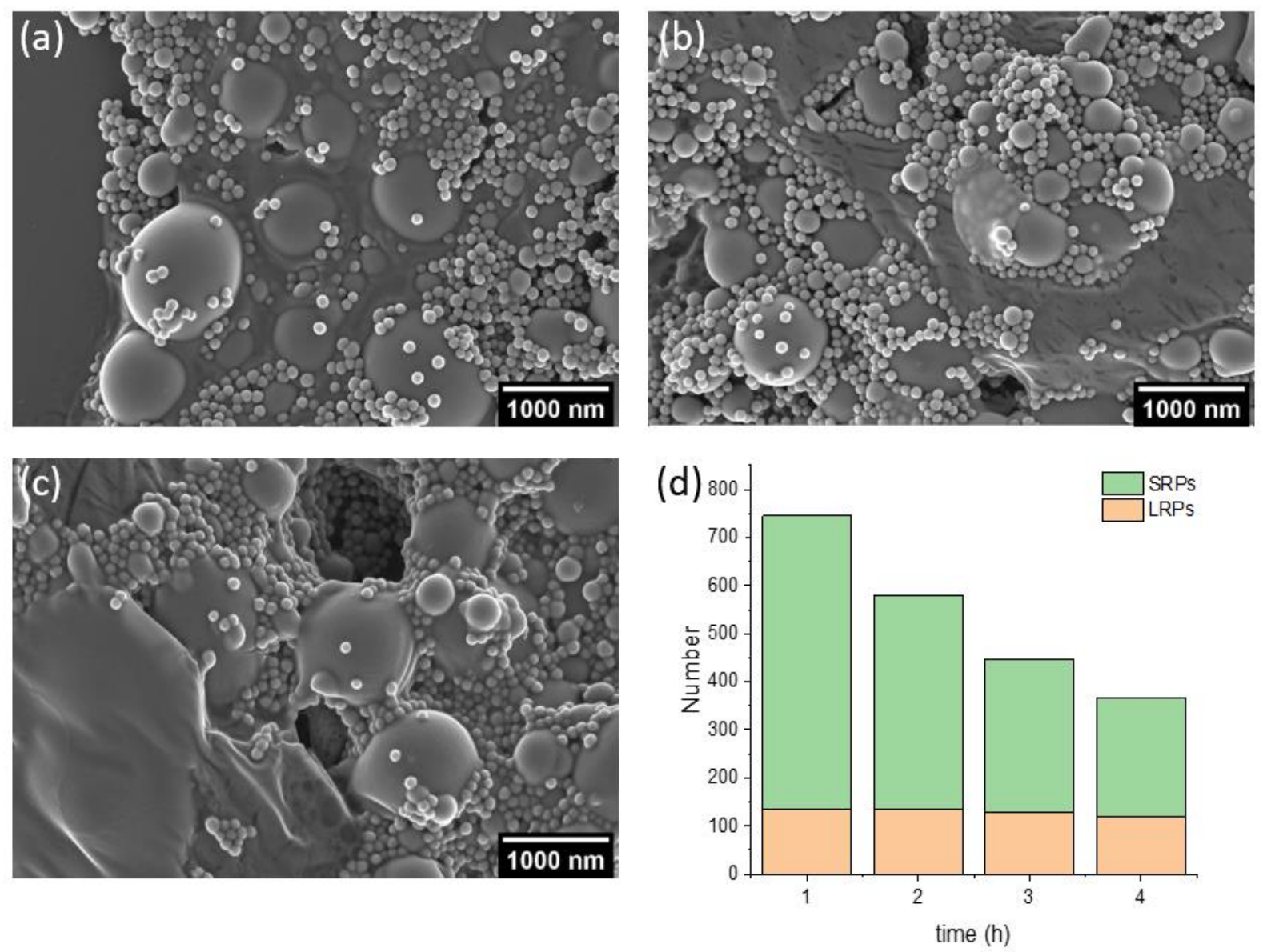

.Figure 4. Structural evolution of $\mathrm{NR}-\mathrm{SiO}_{2} \mathrm{NPs}$ hetero-aggregate during solvent evaporation. SE micrographs showing the structure at (a) $t=2 h$, (b) $t=3 h$, (c) $t=4 h$ (magnification 20000x). (d) Histogram grouping the SRPs and LRPs counts from BSE images acquired between $\mathrm{t}=1 \mathrm{~h}$ and $\mathrm{t}=4 \mathrm{~h}$. 
In order to make progress in the understanding of the structural evolution of the $\mathrm{NR}^{-\mathrm{SiO}_{2} \mathrm{NPs}}$ hetero-aggregate, counting of LRPs and SRPs has been carried out on the structures recorded from $\mathrm{t}=1 \mathrm{~h}$ to $\mathrm{t}=4 \mathrm{~h}$. The hetero-aggregate at $\mathrm{t}=1 \mathrm{~h}$ is found to be composed of $\sim 85 \%$ of SRPs and $15 \%$ of LRPs by number, a ratio between the two types of NR particles similar to the one established by DLS measurements (Figure S1). Interestingly, during solvent evaporation, the globular form of LRPs was retained for longer time than that of SRPs (Figure 4d). This is consistent with the NR particles size: the specific surface area of SRPs is greater than the one of LRPs and thus assuming similar polymer inter-diffusion rates, we expect the loss of the colloidal structure of SRPs at earlier stage than that of LRPs. This observation is in agreement with a previous Atomic Force Microscopy (AFM) study on latex films containing mostly LRPs and SRPs, respectively ${ }^{43}$.

In terms of large-scale processing, it would be interesting to boost the kinetics of the film formation mechanism in order to obtain a material characterized by a homogeneous and cohesive film in a shorter lapse of time. For this reason, mechanical shear was applied on the liquid suspension postmixing of $\mathrm{NR}$ with $\mathrm{SiO}_{2} \mathrm{NPs}$. We have used an original commercial rheo-optical device allowing real time imaging acquisition to investigate the structural evolution of the hetero-aggregate under shear flow. Light transmission images recorded during the applied shearing cycles highlight the formation and combination of aggregates, quickly growing in size leading to a macroscopically visible phase-separated hetero-aggregate (Figure S7a). If approximately $1 \mathrm{~h}$ was needed to induce phase-separation without the application of external stress, only a few shearing cycles (5-10 min) are necessary to form the floating hetero-aggregate. This demonstrates that in presence of ions the application of shear accelerated the formation of the hetero-aggregate. It was also controlled that in the absence of $\mathrm{Mg}^{2+}$ ions, the formation of the hetero-aggregate under shear was not observed (Figure S7b); the mechanical stress was not sufficient to overcome the interaction energy barrier 
caused by the electrostatic repulsion between particles. Thus, the more rapid formation of the NR$\mathrm{SiO}_{2} \mathrm{NPs}$ hetero-aggregate under shear is due to the increased number of collisions between particles. Figure $5 \mathrm{a}$ and $\mathrm{b}$ illustrate the nanoscale structure of the hetero-aggregates formed under shear, while Figure 5c and d refer to a control sample, consisting of a hetero-aggregate formed inside the shearing module, without the application of shear. We can observe that large zones of NR film are present within the hetero-aggregated formed under shear. From this observation, we can state that the application of shear increases the kinetics of film formation mechanism, boosting coalescence and polymer chain interdiffusion between NR globules. For this reason, it is a useful tool in the liquid route to achieve the formation of a film state in a relatively short time.
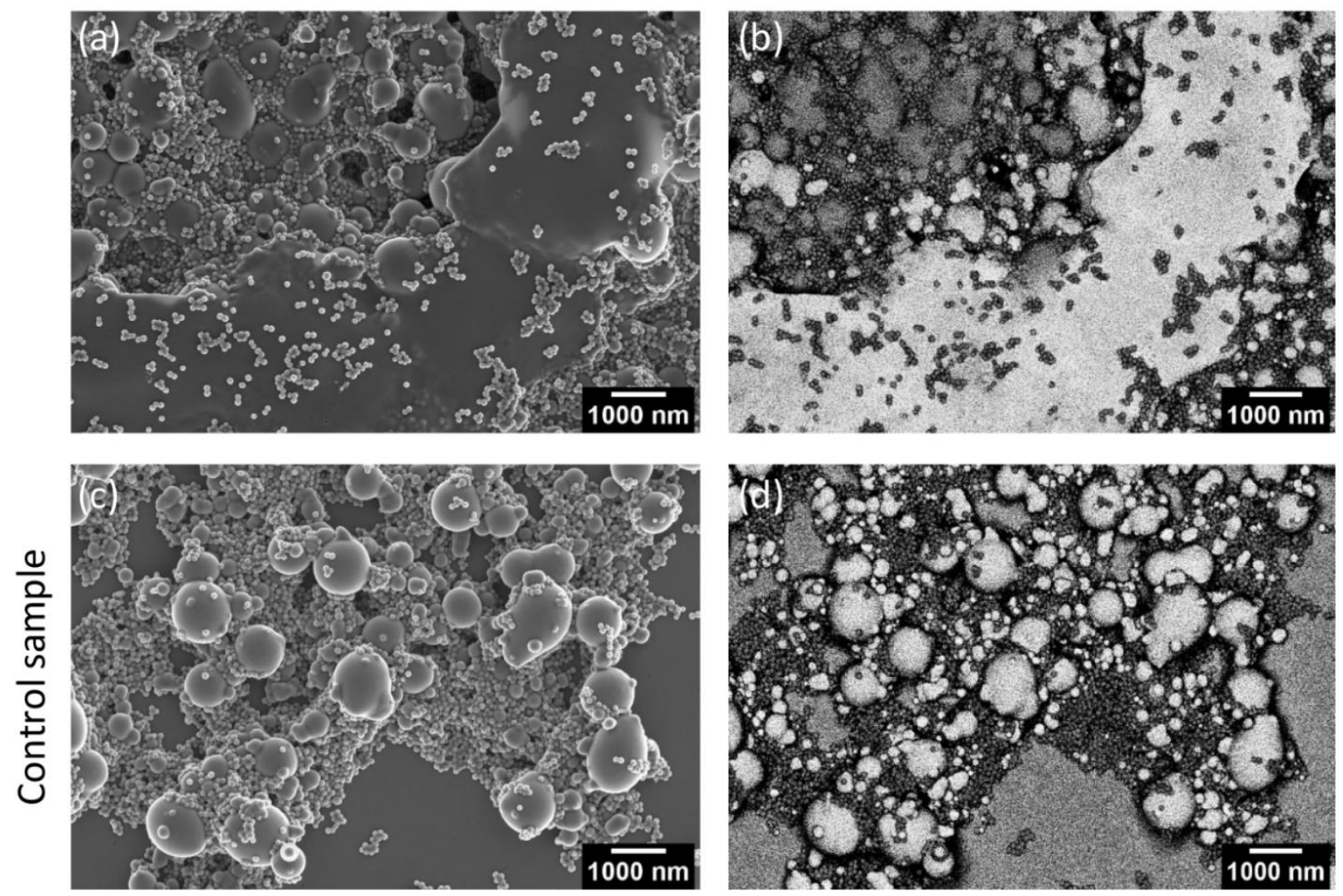

Figure 5. Effect of shear on the structure of the NR-SiO $2 \mathrm{NPs}$ hetero-aggregate. Mechanical shear was applied using the RheOptiCAD module ${ }^{25,44}$. SE (a) and BSE (b) images showing the structure 
of the hetero-aggregate at the end of the 10 oscillation cycles (10 min) (magnification 10000x). SE (c) and BSE (d) micrographs of NR-SiO $2 \mathrm{NPs}$ hetero-aggregate formed at $\mathrm{t}=1 \mathrm{~h}$ inside the shearing module without the application of mechanical shear (magnification 10000x).

\subsection{Structural characterization of $\mathrm{NR}-\mathrm{SiO}_{2} \mathrm{NPs}$ composite}

Regardless to the application of shear, a solid composite is obtained after complete solvent evaporation $(\mathrm{t}=24 \mathrm{~h})$. Its structure shows a smooth and homogeneous NR film with embedded $\mathrm{SiO}_{2} \mathrm{NPs}$ (Figure 6a and b). In such composite, the filler particles appear homogeneously dispersed in the film and regularly organized as ring-ellipse like structures (red arrows in Figure 6b).
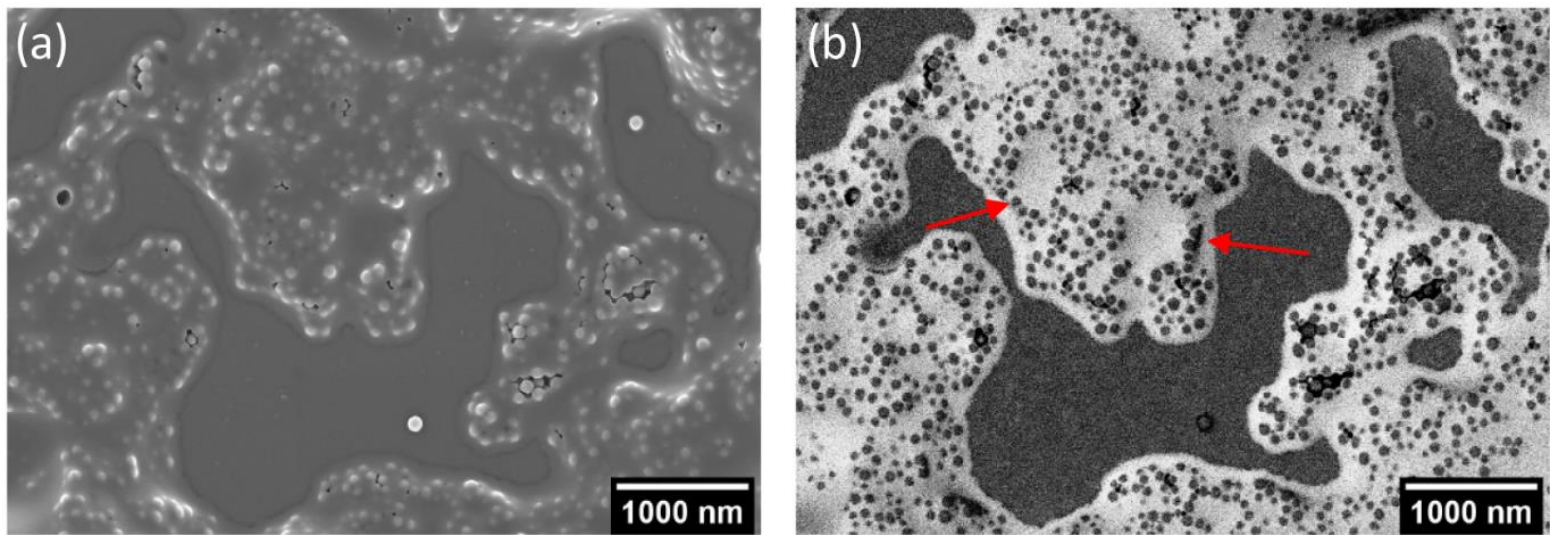

Figure 6. FESEM micrographs of $\mathrm{NR}-\mathrm{SiO}_{2} \mathrm{NPs}$ composite obtained after complete solvent evaporation at $\mathrm{t}=24 \mathrm{~h}$. (a) $\mathrm{SE}$ and (b) $\mathrm{BSE}$ images showing the NR matrix with embedded $\mathrm{SiO}_{2}$ nanoparticles (magnification 20000x). Red arrows in (b) indicate typical ring-ellipse like structures.

At this stage, AFM-IR was employed to investigate more deeply the arrangement of $\mathrm{SiO}_{2} \mathrm{NPs}_{\text {in }}$ the obtained composite. This hybrid technique coupling the spatial resolution of AFM with the chemical characterization of IR spectroscopy is capable of providing information arising from a depth $>1 \mu \mathrm{m}$. Prior to the AFM-IR study, the IR response of $\mathrm{NR}$ and $\mathrm{SiO}_{2} \mathrm{NPs}$ as well as the AFM topography of the composite were investigated. The latter confirmed the presence of complete 
filmified NR matrix containing embedded $\mathrm{SiO}_{2} \mathrm{NPs}$ (Figure 7a), in good agreement with our previous FESEM measurements probing the sample surface. The FTIR absorption spectra of NR and $\mathrm{SiO}_{2}$ recorded in the region between 1800 and $900 \mathrm{~cm}^{-1}$ are reported in Figure S8. For NR, a strong absorption band centered at $1450 \mathrm{~cm}^{-1}$ is observed corresponding to the $\mathrm{CH}_{2}$ deformation typical of polyisoprene ${ }^{45}$. On the other hand, the IR spectra of $\mathrm{SiO}_{2} \mathrm{NPs}$ show a strong absorption band with a maximum at $1100 \mathrm{~cm}^{-1}$, corresponding to the asymmetric Si-O-Si stretching. Those wavenumbers were chosen to record IR maps of both the NR matrixmainly composed of polyisoprene, and that of $\mathrm{SiO}_{2} \mathrm{NPs}$ within the film (Figure $7 \mathrm{~b}$ and c).
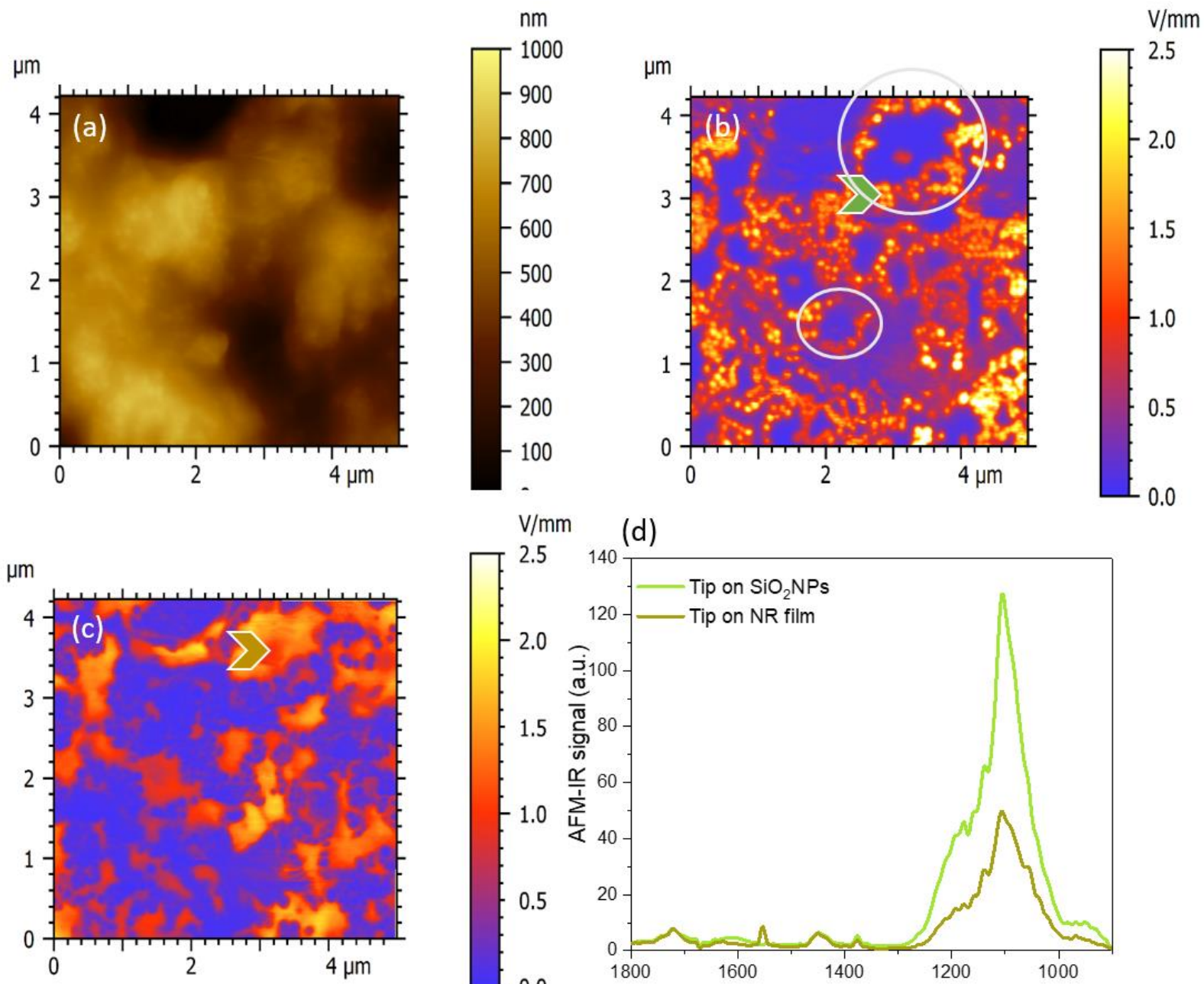

(e)
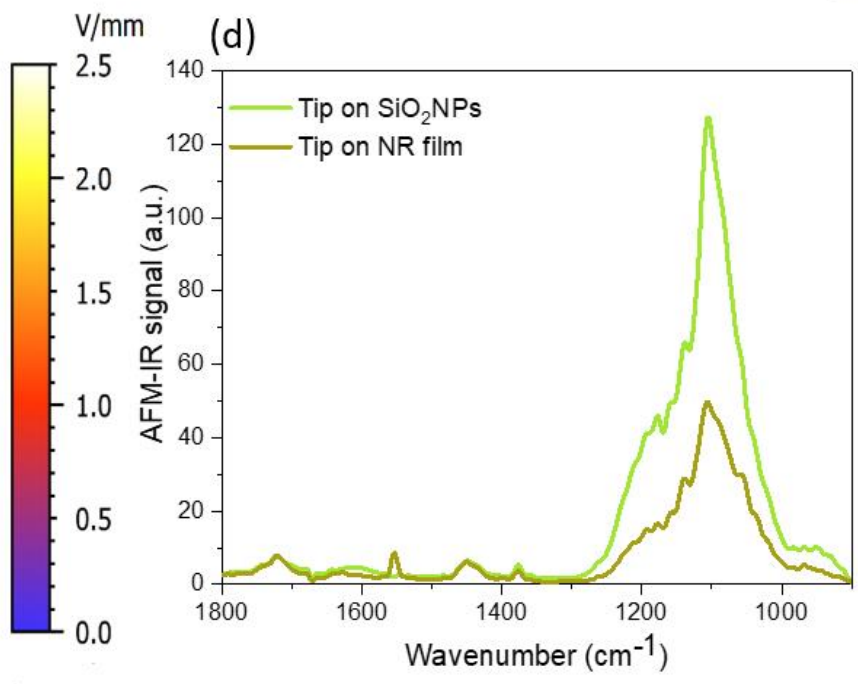
Figure 7. $\mathrm{SiO}_{2} \mathrm{NPs}$ distribution in the obtained composite at $\mathrm{t}=24 \mathrm{~h}$. AFM (a) height image. (b) IR map at $1100 \mathrm{~cm}^{-1}$ of the corresponding region referring to Si-O-Si asymmetric stretching. The circled areas highlight a specific arrangement of $\mathrm{SiO}_{2} \mathrm{NPs}$ in ellipse-ring like structures. (c) IR map at $1450 \mathrm{~cm}^{-1}$ referring to the $\mathrm{CH}_{2}$ deformation typical of polyisoprene of NR. In both cases, the red and blue colors correspond to high and low level of IR absorption, respectively. (d) Local IR spectra acquired in specific location of interest indicated by arrows in (b) and (c), and corresponding FTIR spectra of $\mathrm{SiO}_{2} \mathrm{NPs}$ and NR inserted as inset.

Results show that the IR map of the NR matrix recorded at $1450 \mathrm{~cm}^{-1}$ represents the negative image of the one recorded at $1100 \mathrm{~cm}^{-1}$ corresponding to the detection of $\mathrm{SiO}_{2} \mathrm{NPs}$. The latter are found interconnected forming a network, which is regularly organized in ring-ellipse structures as previously observed at the sample surface by FESEM (Figure 6). The size of the ring-ellipse structure ranges between $250-2000 \mathrm{~nm}$, similar to the diameters of the NR globules in their initial colloidal form. This result suggests that during solvent evaporation, the NR globules undergo a film formation process while $\mathrm{SiO}_{2}$ nanoparticles are maintained in place leading to the observed ring-ellipse structures, corresponding to reminiscent shapes of the NR globules. The local IR spectra recorded placing the AFM tip on the absorbing structure corresponding to $\mathrm{SiO}_{2} \mathrm{NPs}_{\text {(green }}$ arrow in Figure $7 \mathrm{~b}$ ) showed minor peaks between $1300 \mathrm{~cm}^{-1}$ and $1800 \mathrm{~cm}^{-1}$ and a major peak at $1100 \mathrm{~cm}^{-1}$ (Figure 7d). This confirms that the absorbing structure on the IR map recorded at 1100 $\mathrm{cm}^{-1}$ refers to $\mathrm{SiO}_{2} \mathrm{NPs}$ which are at least partially covered by the NR film. Noteworthy, the local IR spectra recorded on a large area of NR film (yellow arrow in Figure 7c) also revealed the presence of an absorption band at $1100 \mathrm{~cm}^{-1}$, proving the presence of fillers in deeper layers within the NR matrix. The same experiment was then repeated for the composite obtained after the application of shear in liquid suspension (Figure S9). A similar distribution and arrangement, with 
no more aggregation of the fillers was observed. Thus, shear applied post-mixing NR with $\mathrm{SiO}_{2} \mathrm{NPs}$ did not alter the distribution of the fillers, which are again very often found in ring ellipselike structures of similar sizes as the ones previously reported. This result is an indicator of a strong initial interaction between the biomembrane components of $\mathrm{NR}$ globules and $\mathrm{SiO}_{2} \mathrm{NPs}$, and it also confirms a restricted motion of the fillers during the film formation process.

In addition to $\mathrm{SiO}_{2} \mathrm{NPs}$ distribution, the spatial organization of proteins and lipids and their possible interaction with $\mathrm{SiO}_{2} \mathrm{NPs}$ in the composite are interesting subjects which can impact material properties. For this purpose, d-STORM fluorescence microscopy was used to decipher the distribution of proteins and lipids of NR in the obtained dried composite, with respect to $\mathrm{SiO}_{2}$ NPs. Results were then compared with the distribution of these biomolecules in a NR film formed with the same protocol, but in the absence of the fillers. A very different behavior was observed. When $\mathrm{SiO}_{2} \mathrm{NPs}$ are embedded in the NR film, d-STORM micrographs indicate the presence of clusters of proteins (red) and lipids (green) (Figure 8c and e). Outside these clustered domains, we observed mainly dispersed and small aggregates of proteins and lipids. Additionally, clusters of proteins and lipids overlapping with each other are also present, suggesting a possible co-assembly. On the other hand, in the absence of $\mathrm{SiO}_{2} \mathrm{NPs}$, proteins and lipids are organized in much smaller domains, leading to a different spatial organization (Figure 8d and f). Detailed image analysis was then performed to have a quantitative description of the proteins and lipids organization within the composite. The maps obtained from DBSCAN analysis ascertain the pronounced clustering of proteins and lipids within the NR film when $\mathrm{SiO}_{2} \mathrm{NPs}$ are present (Figure S10 and S11). 

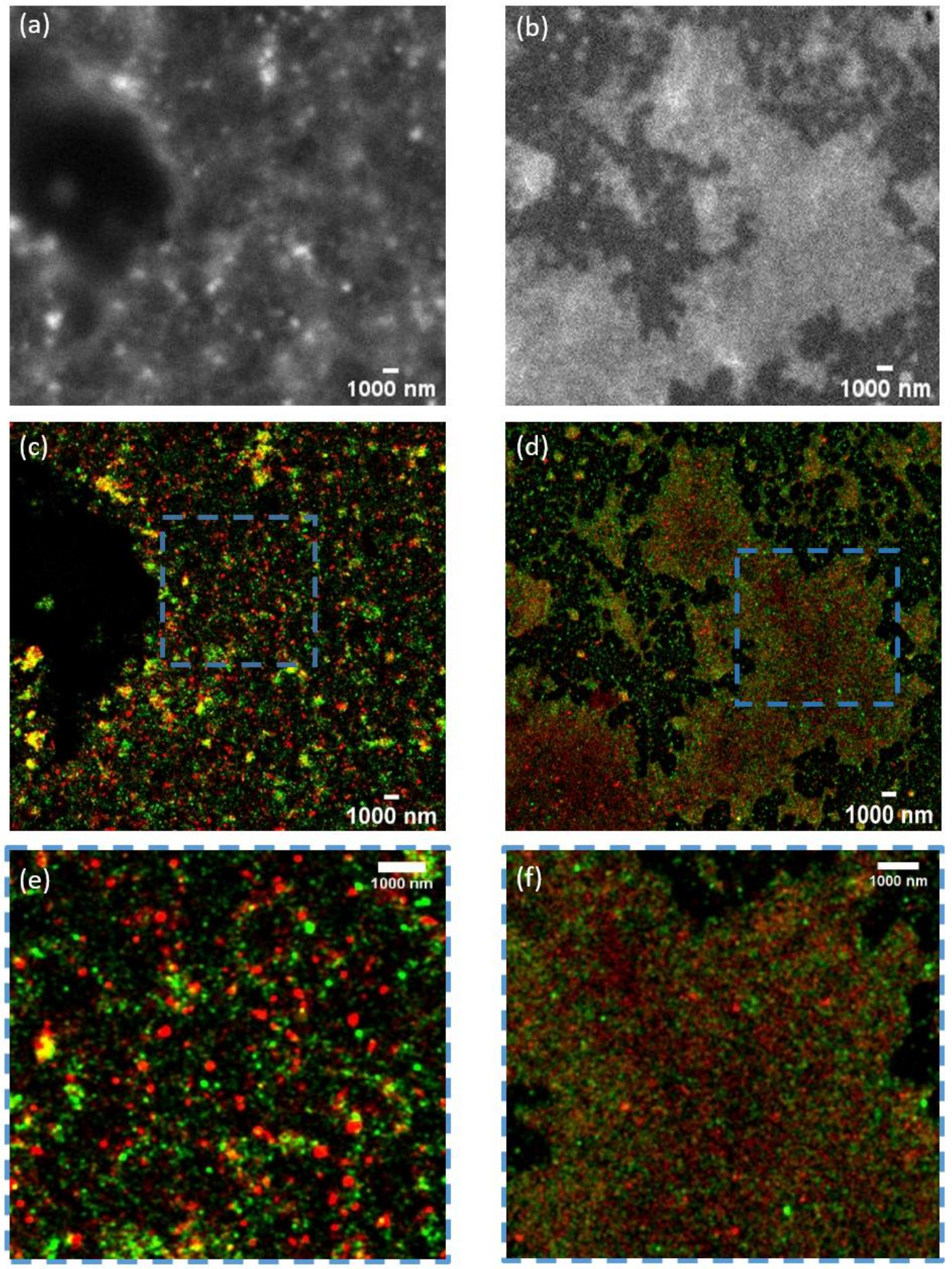

(g)

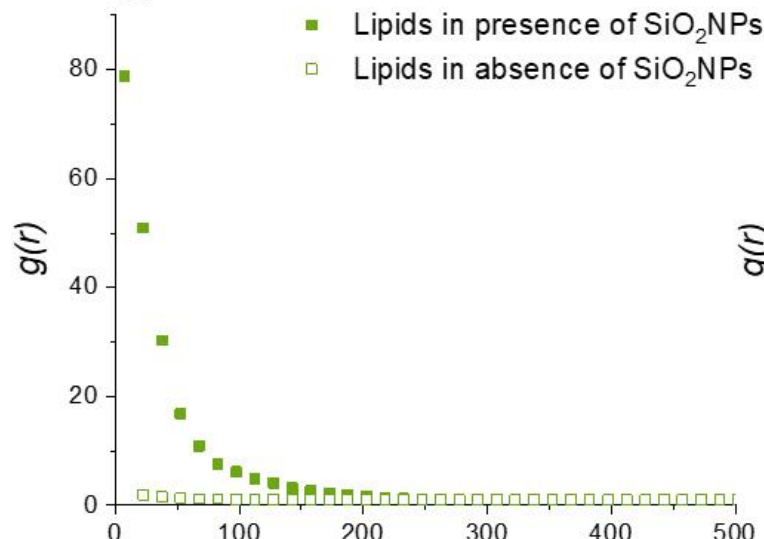

(h)

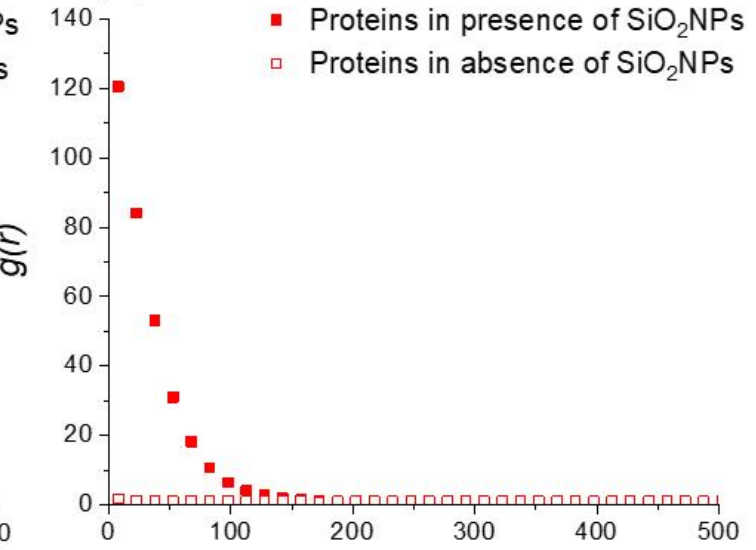


Figure 8. Distribution of proteins and lipids in $\mathrm{NR}-\mathrm{SiO}_{2} \mathrm{NPs}$ composite and NR film at $\mathrm{t}=24 \mathrm{~h}$, formed by coagulation in presence of $\mathrm{Mg}^{2+}$ (ionic strength $=0.1 \mathrm{M}$ ), and drying. Epifluorescence images of (a) NR-SiO 2 NPs composite and (b) NR film. Dual color d-STORM fluorescence image of proteins (red) and lipids (green) of the corresponding (c) NR-SiO 2 NPs composite and (d) NR film. (e), (f) Magnified view of the boxed region (image size: $\sim 10 \times 10 \mu \mathrm{m}$ ) in (c), and (d), respectively, showing a difference in the distribution of proteins and lipids between the NR film and the NR-SiO ${ }_{2} \mathrm{NPs}$ composite. Proteins and lipids show a marked clustering in the NR-SiO $2 \mathrm{NPs}$ composite. 2D coordinate-based auto-correlation analysis of lipids (g) and proteins $(\mathrm{h})$ in the NR$\mathrm{SiO}_{2} \mathrm{NPs}$ composite ( $\square$ ) and in NR matrix in absence of $\mathrm{SiO}_{2} \mathrm{NPs}(\square)$. Proteins and lipids autocorrelation function in the composite highlighted similar trends with an increase of the pair correlation function $g(r)$ at distances $<200 \mathrm{~nm}$.

Then, a 2D coordinate based pair-correlation analysis was used to define the size of the reported clusters. Typical pair-correlation functions $g(r)$ obtained for proteins and lipids in the NR-SiO $2 \mathrm{NPs}$ composite show a rapid increase of the pair correlation $g(r)$ at distances $<200 \mathrm{~nm}$ (Figure $8 \mathrm{~g}$ and h). This distance defines the typical protein and lipid clusters size; at much larger distances $g(r)$ tends to one, meaning that the position between proteins (resp. between lipids) becomes uncorrelated. On the other hand, when $\mathrm{SiO}_{2} \mathrm{NPs}$ are not present in the NR matrix, the paircorrelation function of the biomolecules does not show any significant increase of the function at small distances, revealing that proteins and lipids clusters are only found in the NR-SiO ${ }_{2} \mathrm{NPs}$ composite.

By comparison, the spatial distribution of proteins and lipids in the biomembrane of NR in the liquid state (Figure 3) does not show any clustering of the biomolecules. To assess at which stage of the film formation process clustering occurs, we performed d-STORM measurements on the 
hetero-aggregate at $\mathrm{t}=4 \mathrm{~h}$, focusing on the leftover colloidal form of NR globules (Figure S12). Images highlight the presence of clustered domains of proteins and lipids (Figure S9a). Additionally, the corresponding pair-correlation analysis of the biomolecules reported a very similar trend as the ones previously described for the $\mathrm{NR}-\mathrm{SiO}_{2} \mathrm{NPs}$ composite (Figure $\mathrm{S} 9 \mathrm{~b}$ and c). This indicates that clustering occurs during the film formation process of NR. Furthermore, to control whether the presence of the ionic medium $\left(\mathrm{Mg}^{2+} \mathrm{IS}=0.1 \mathrm{M}\right)$ could have any influence on the clustering behavior of proteins and lipids, the distribution of the biomolecules and the related cluster analysis have been run for a NR-SiO ${ }_{2} \mathrm{NPs}$ composite prepared by simply drying the binary colloidal suspension in distilled water. Both qualitative and quantitative results confirmed a distribution of proteins and lipids with no spatial correlation, comparable to the one referred to the NR film in the absence of the fillers (Figure S1). Altogether, these results indicate a $\mathrm{SiO}_{2} \mathrm{NPs}-$ induced clustering mechanism of proteins and lipids of NR, occurring during the process of NR globule destructuration and polyisoprene chain inter-diffusion, in which the $\mathrm{Mg}^{2+}$ ions play an important role.

To further explore where $\mathrm{SiO}_{2} \mathrm{NPs}$ are located with respect to the proteins and lipids clusters, CLEM measurements combining dual color d-STORM acquisitions and FESEM experiments were performed. Here $\mathrm{SiO}_{2} \mathrm{NPs}$ are used as a bifunctional probe visible by both microscopy techniques. Typical d-STORM micrographs labelling lipids and $\mathrm{SiO}_{2} \mathrm{NPs}$ and the corresponding FESEM image are shown in Figure 9. The large view SE image shows the overall structure of the NR$\mathrm{SiO}_{2} \mathrm{NPs}$ composite (Figure 9a), confirming a complete loss of the original spherical form of the NR globules in favour of a film formation process. The magnified view of this structure is presented with a BSE image (Figure 9b) and its corresponding Si d-STORM micrograph (Figure 9c). Note that, although shrinkage effects induced by the high vacuum condition of FESEM 
experiments cannot be excluded, common structures of $\mathrm{SiO}_{2} \mathrm{NPs}$ organized in ring-ellipse like structures are shown by both micrographs (red circle in Figure $9 \mathrm{~b}$ and c), confirming a correct detection of $\mathrm{SiO}_{2} \mathrm{NPs}$ by fluorescence measurements. Noteworthy, the dual colour d-STORM micrograph superposing the fluorescence of lipids with the one of $\mathrm{SiO}_{2} \mathrm{NPs}$ certified the presence of lipid clusters and showed that such domains are found in close proximity of the fillers (Figure 9d). 

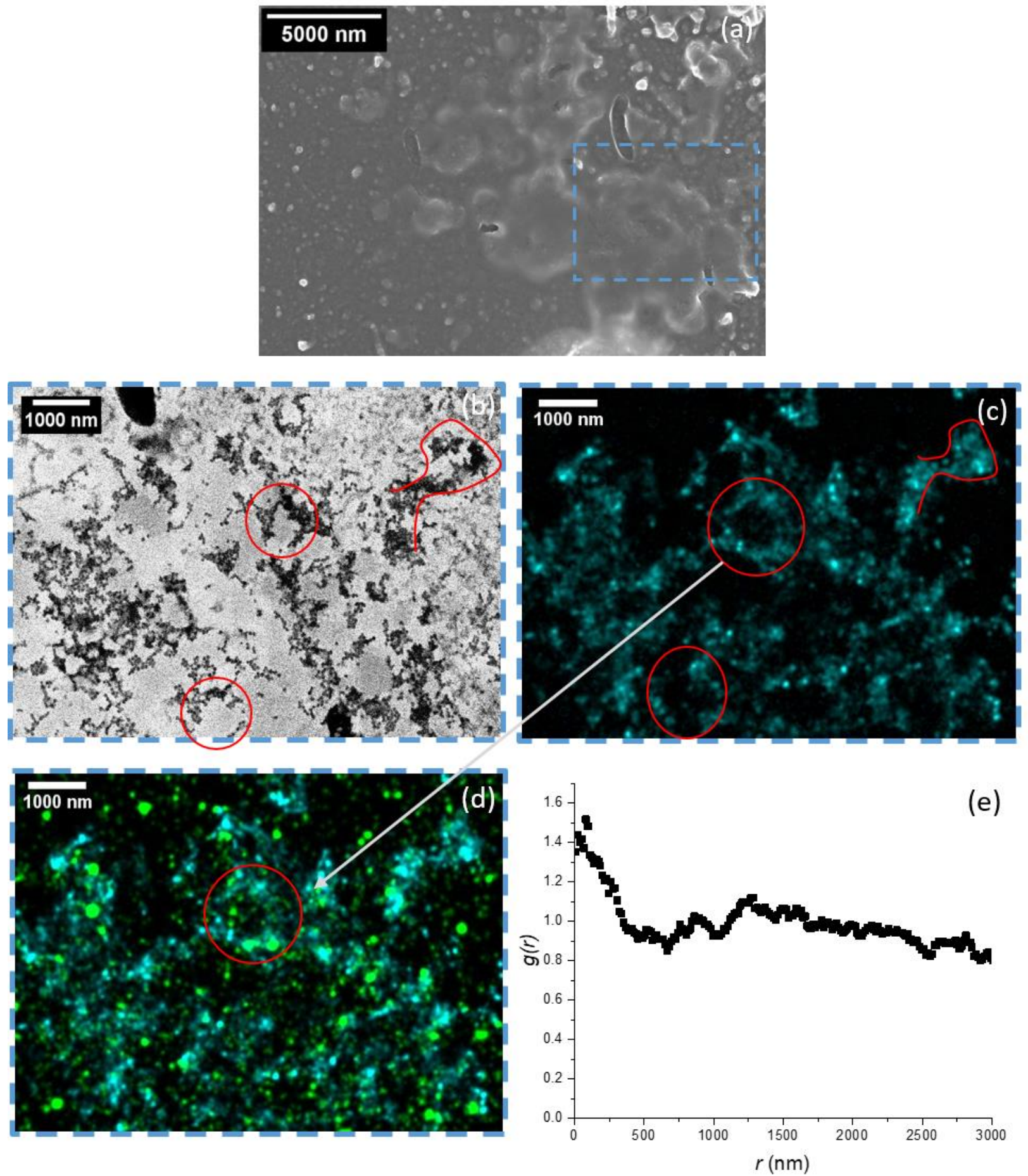
Figure 9. CLEM on the NR-SiO 2 NPs composite labelling $\mathrm{SiO}_{2} \mathrm{NPs}$ and lipids. (a) SE large view. (b) Magnified BSE image of the blue boxed region in (a). (c) d-STORM micrographs of $\mathrm{SiO}_{2} \mathrm{NPs}$ (cyan). (d) Dual color d-STORM micrographs combining the fluorescence signals of $\mathrm{SiO}_{2} \mathrm{NPs}$ (cyan) and lipids (green), obtained with sequential acquisitions and recorded in the blue boxed region of (a) showing the presence of lipid clusters in close proximity to fillers structures. (e) Cross-correlation analysis correlating the fluorescence signal of lipids with the one of $\mathrm{SiO}_{2} \mathrm{NPs}$, showing an increase of the pair correlation function $g(r)$ at distances $<400 \mathrm{~nm}$.

To assess their possible interaction, cross-correlation analysis was run between the fluorescence signal of lipids and the one referred to silica fillers. The resulting pair correlation function $g(r)$ between $\mathrm{SiO}_{2} \mathrm{NPs}$ and lipids shows an increase at distances $<400 \mathrm{~nm}$ indicating appreciable spatial colocalization of lipids aggregates and the fillers (Figure 9e). Similar results in terms of imaging and coordinate-based correlation analysis have been obtained for proteins with respect to $\mathrm{SiO}_{2} \mathrm{NPs}$ (Figure S14). Altogether, these results strongly suggested an interaction between lipids and proteins clusters with $\mathrm{SiO}_{2} \mathrm{NPs}$ in the composite. Since no clustering was observed in absence of $\mathrm{Mg}^{2+}$, we can conclude that the divalent ions still partake in a bridging effect that stimulates this interaction, as it occurred in the liquid state. The aforementioned experimental findings are supported by a recent work by Sattar et $a .^{20}$ which provides insights into the molecular scale interactions present in the optimized structure of a $\mathrm{NR}-\mathrm{SiO}_{2} \mathrm{NPs}_{\text {s }}$ composite using molecular dynamics simulations. The authors reported the presence of two possible attractive H-bonds between NR protein and the silica surface, plus the formation of a salt-ion bridge. The first H-bond has been identified between the $\alpha-\mathrm{NH}$ group and the surface oxygen atoms of $\mathrm{SiO}_{2} \mathrm{NPs}$, and the second one taking place between the carboxylic oxygen and the surface silanol. Moreover, there is attractive electrostatic interaction between negatively charged oxygen atoms of NR lipids and 
the silanol surface group of $\mathrm{SiO}_{2} \mathrm{NPs}$ mediated by $\mathrm{Mg}^{2+}$ ions acting as a salt bridge. Overall, our experimental evidence correlates well with the previously reported theoretical findings on the subject, contributing to the understanding of molecular scale mechanisms occurring in composites of interest for the tire industry.

\section{CONCLUSIONS}

In this study, we have used a set of powerful nanoscale imaging techniques to report a comprehensive characterization of the nanoscale structure and its evolution with time of a model liquid mixing system with potential industrial relevance for tire applications.

We first described the structure of the NR-SiO ${ }_{2} \mathrm{NPs}$ hetero-aggregate formed by destabilization in presence of divalent cations. We report the presence of $\mathrm{SiO}_{2} \mathrm{NPs}$ surrounding NR globules due to an electrolyte-responsive interaction, between NR and the fillers particles mediated by $\mathrm{Mg}^{2+}$ ions. FESEM measurements proved that such an interaction does not trigger a film formation mechanism, but prevents coalescence between the globules instead. Using d-STORM, we have also shown that the architecture of the biomembrane in terms of proteins and lipids distribution is unchanged during the interaction of the NR globules with $\mathrm{SiO}_{2} \mathrm{NPs}$, limiting the transition towards a film state. Such a transition can be achieved by the application of shear in liquid suspension or by evaporation of the solvent. The advantage of shear is that it accelerates the dynamic of heteroaggregation as well as boosting coalescence between NR globules achieving the formation of a composite in relatively short time. It is therefore an important parameter in terms of processing. Regardless of the applied shear, a composite is obtained after complete evaporation of the solvent. The experiments conducted using AFM-IR demonstrates a strict mobility of $\mathrm{SiO}_{2} \mathrm{NPs}$ during film formation. The latter are found in the composite forming a network regularly organized in 
ellipsoidal-ring like structures which are reminiscent shapes of the original NR globular forms. Thus, the dispersion of $\mathrm{SiO}_{2} \mathrm{NPs}$ in the composite is intimately related to the liquid-state interaction established with the NR globules, taking advantage of their spherical structure. For a more complete characterization of the composite, d-STORM was again employed to unravel lipids and proteins distribution with respect to $\mathrm{SiO}_{2} \mathrm{NPs}$. In this material, proteins and lipids organized themselves in cluster domains which are found partly colocalized with $\mathrm{SiO}_{2} \mathrm{NPs}$, highlighting an interaction between them. In this context, a microscopic understanding of the interaction mechanism would be of great interest. Overall, our study reports a complete nanostructural characterization of the relevant components, including biomolecules, during the evolution of the system from the hydrated hetero-aggregate to a dried composite material. We believe that our work contributes to the understanding of complex NR-based composites obtained by liquid coagulation while unlocking the potential of high-resolution imaging techniques applied to materials, in particular tire treads. Our approach can be further leveraged opening up to several perspectives. For example, further investigation aiming to establish a relation between the final aforementioned $\mathrm{SiO}_{2} \mathrm{NPs}$ arrangement found in the composite and the material mechanical properties will be of interest. Ultimately, in the manufacturing procedures, composites obtained after coagulation by liquid route are usually further processed with mechanical treatments, during which the organization of the fillers might evolve. A scope for future work would be to apply the nanoscale approach reported here to investigate a possible evolution of the filler organization in the reported $\mathrm{NR}-\mathrm{SiO}_{2} \mathrm{NPs}$ system as well as study other NR-industrial aggregate silica systems and further explore the structure property relationship of those materials of interest for tire applications. 


\section{ASSOCIATED CONTENT}

\section{Supporting Information.}

The following files are available free of charge.

DLS measurements on NR latex and $\mathrm{SiO}_{2} \mathrm{NPs}$ in suspension (Figure $\mathrm{S} 1$ ), additional $\mathrm{SE}$ micrographs on NR globules at the end of 10 oscillation shearing cycles (Figure S2), Uv-Vis absorption and emission spectra of the fluorophores used for d-STORM acquisitions (Figure S3) as well tests conducted to exclude any possible interaction among them (Figure S4), a large view SE image of the correlative support used to performed CLEM (Figure S5), SE and (b) BSE micrographs of the NR-SiO $2 \mathrm{NPs}$ hetero-aggregate obtained in presence of $\mathrm{Mg}^{2+}$ ions (Figure S6), optical images recorded along with shearing oscillation cycles (Figure S7), FTIR spectra of NR and $\mathrm{SiO}_{2} \mathrm{NPs}$ (Figure S8), AFM and AFMIR micrographs recorded on the composite obtained after shear application (Figure S9) DBSCAN cluster analysis (Figure S10 and S11), distribution of proteins and lipids in NR-SiO 2 NPs hetero-aggregate at $\mathrm{t}=4 \mathrm{~h}$ (Figure $\mathrm{S} 12$ ), distribution of proteins and lipids in $\mathrm{NR}-\mathrm{SiO}_{2} \mathrm{NPs}$ composite formed in absence of $\mathrm{Mg}^{2+}$ ions (Figure S13), CLEM micrograph labelling silica and proteins (Figure S14) (PDF)

\section{AUTHOR INFORMATION}

\section{Corresponding Author}

*E-mail: gianluca.cattinari@u-psud.fr/gianluca.cattinari@michelin.com

\section{Author Contributions}

The manuscript was written through contributions of all authors. All authors have given approval to the final version of the manuscript. 


\section{Funding Sources}

This work was supported by grants from Michelin and Université Paris-Saclay.

\section{ACKNOWLEDGMENT}

We thank Michaël Trichet (Electron Microscopy Facility, Institut de Biologie Paris-Seine FR3631) for his FESEM expertise and helpful technical advice. We also thank Ludivine Houel-Renault for technical assistance during sample preparation and for the access to the CPBM biochemistry room.

\section{REFERENCES}

(1) Encyclopedia of Materials: Science and Technology; Buschow, K. H. J., Ed.; Elsevier: Amsterdam; New York, 2001.

(2) Sahakaro, K. Mechanism of Reinforcement Using Nanofillers in Rubber Nanocomposites. In Progress in Rubber Nanocomposites; Elsevier, 2017; pp 81-113. https://doi.org/10.1016/B978-0-08-100409-8.00003-6.

(3) Donnet, J.-B.; Custodero, E. Reinforcement of Elastomers by Particulate Fillers. In Science and Technology of Rubber; Elsevier, 2005; pp 367-400. https://doi.org/10.1016/B978012464786-2/50011-0.

(4) Sarkawi, S. S.; Dierkes, W. K.; Noordermeer, J. W. M. Elucidation of Filler-to-Filler and Filler-to-Rubber Interactions in Silica-Reinforced Natural Rubber by TEM Network Visualization. European Polymer Journal 2014, 54, 118-127. https://doi.org/10.1016/j.eurpolymj.2014.02.015.

(5) Dierkes, W.; Blume, A. Silica Reinforcement. In Encyclopedia of Polymeric Nanomaterials; Kobayashi, S., Müllen, K., Eds.; Springer Berlin Heidelberg: Berlin, Heidelberg, 2014; pp 1-7. https://doi.org/10.1007/978-3-642-36199-9_307-1.

(6) Kumar, S. K.; Ganesan, V.; Riggleman, R. A. Perspective: Outstanding Theoretical Questions in Polymer-Nanoparticle Hybrids. J. Chem. Phys. 2017, 147 (2), 020901. https://doi.org/10.1063/1.4990501.

(7) Kaewsakul, W. Silica-Reinforced Natural Rubber for Low Rolling Resistance, EnergySaving Tires: Aspects of Mixing, Formulation and Compatibilization, PhD Thesis, University of Twente, Faculty of Engineering Technology, 2013.

(8) Stöckelhuber, K. W.; Svistkov, A. S.; Pelevin, A. G.; Heinrich, G. Impact of Filler Surface Modification on Large Scale Mechanics of Styrene Butadiene/Silica Rubber Composites. Macromolecules 2011, 44 (11), 4366-4381. https://doi.org/10.1021/ma1026077.

(9) Baeza, G. P.; Genix, A.-C.; Degrandcourt, C.; Petitjean, L.; Gummel, J.; Schweins, R.; Couty, M.; Oberdisse, J. Effect of Grafting on Rheology and Structure of a Simplified Industrial Nanocomposite Silica/SBR. Macromolecules 2013, 46 (16), 6621-6633. https://doi.org/10.1021/ma401016d. 
(10) Baeza, G. P.; Genix, A.-C.; Degrandcourt, C.; Petitjean, L.; Gummel, J.; Couty, M.; Oberdisse, J. Multiscale Filler Structure in Simplified Industrial Nanocomposite Silica/SBR Systems Studied by SAXS and TEM. Macromolecules 2013, 46 (1), 317-329. https://doi.org/10.1021/ma302248p.

(11) Thomas, S.; Chan, C. H.; Pothen, L. A.; Joy, J. P.; Maria, H. J. Natural Rubber Materials: Volume 2: Composites and Nanocomposites; Royal Society of Chemistry, 2013.

(12) Rochette, C. N.; Crassous, J. J.; Drechsler, M.; Gaboriaud, F.; Eloy, M.; de Gaudemaris, B.; Duval, J. F. L. Shell Structure of Natural Rubber Particles: Evidence of Chemical Stratification by Electrokinetics and Cryo-TEM. Langmuir 2013, 29 (47), 14655-14665. https://doi.org/10.1021/1a4036858.

(13) Berthelot, K.; Lecomte, S.; Estevez, Y.; Zhendre, V.; Henry, S.; Thévenot, J.; Dufourc, E. J.; Alves, I. D.; Peruch, F. Rubber Particle Proteins, HbREF and HbSRPP, Show Different Interactions with Model Membranes. Biochimica et Biophysica Acta (BBA) - Biomembranes 2014, 1838 (1), 287-299. https://doi.org/10.1016/j.bbamem.2013.08.025.

(14) Oberdisse, J. Aggregation of Colloidal Nanoparticles in Polymer Matrices. Soft Matter 2006, 2 (1), 29-36. https://doi.org/10.1039/B511959F.

(15) Wang, T.; Wang, M.; Shell, J.; Vejins, V.; Yao-ling, F.; Guo-qiang, F.; Zheng, J. CEC and Its Application in Off-the-Road Tires. Rubber World, 2003, 33, 6.

(16) Sattar, M. A.; Gangadharan, S.; Patnaik, A. Design of Dual Hybrid Network Natural Rubber-SiO 2 Elastomers with Tailored Mechanical and Self-Healing Properties. ACS Omega 2019, 4 (6), 10939-10949. https://doi.org/10.1021/acsomega.9b01243.

(17) Di Credico, B.; Tagliaro, I.; Cobani, E.; Conzatti, L.; D’Arienzo, M.; Giannini, L.; Mascotto, S.; Scotti, R.; Stagnaro, P.; Tadiello, L. A Green Approach for Preparing HighLoaded Sepiolite/Polymer Biocomposites. Nanomaterials 2018, 9 (1), 46. https://doi.org/10.3390/nano9010046.

(18) Berriot J. De Gaudemaris B. Laffargue G. Method for preparing a masterbatch of natural rubber and silica, US Patent No 2012/0264875 A1. US Patent and Trademark Office

(19) Chan, A. J.; Steenkeste, K.; Canette, A.; Eloy, M.; Brosson, D.; Gaboriaud, F.; FontaineAupart, M.-P. Natural Rubber-Filler Interactions: What Are the Parameters? Langmuir 2015, 31 (45), 12437-12446. https://doi.org/10.1021/acs.langmuir.5b03244.

(20) Sattar, Md. A.; Nair, A. S.; Xavier, P. J.; Patnaik, A. Natural Rubber-SiO 2 Nanohybrids: Interface Structures and Dynamics. Soft Matter 2019, 15 (13), 2826-2837. https://doi.org/10.1039/C9SM00254E.

(21) Genix, A.-C.; Oberdisse, J. Structure and Dynamics of Polymer Nanocomposites Studied by X-Ray and Neutron Scattering Techniques. Current Opinion in Colloid \& Interface Science 2015, 20 (4), 293-303. https://doi.org/10.1016/j.cocis.2015.10.002.

(22) Karino, T.; Ikeda, Y.; Yasuda, Y.; Kohjiya, S.; Shibayama, M. Nonuniformity in Natural Rubber As Revealed by Small-Angle Neutron Scattering, Small-Angle X-Ray Scattering, and Atomic Force Microscopy. Biomacromolecules 2007, 8 (2), 693-699. https://doi.org/10.1021/bm060983d.

(23) Boonsomwong, K.; Genix, A.-C.; Chauveau, E.; Fromental, J.-M.; Dieudonné-George, P.; Sirisinha, C.; Oberdisse, J. Rejuvenating the Structure and Rheological Properties of Silica Nanocomposites Based on Natural Rubber. Polymer 2020, 189, 122168. https://doi.org/10.1016/j.polymer.2020.122168. 
(24) Musino, D.; Genix, A.-C.; Chauveau, E.; Bizien, T.; Oberdisse, J. Structural Identification of Percolation of Nanoparticles. Nanoscale 2020, 12 (6), 3907-3915. https://doi.org/10.1039/C9NR09395H.

(25) Boitte, J.-B.; Vizcaïno, C.; Benyahia, L.; Herry, J.-M.; Michon, C.; Hayert, M. A Novel Rheo-Optical Device for Studying Complex Fluids in a Double Shear Plate Geometry. Review of Scientific Instruments 2013, 84 (1), 013709. https://doi.org/10.1063/1.4774395.

(26) Chan, A. J.; Steenkeste, K.; Eloy, M.; Brosson, D.; Gaboriaud, F.; Fontaine-Aupart, M.-P. LIPID CONTENT IN SMALL AND LARGE NATURAL RUBBER PARTICLES. Rubber Chemistry and Technology 2015, 88 (2), 248-257. https://doi.org/10.5254/rct.15.85938.

(27) Cattinari, G.; Steenkeste, K.; Bris, C.; Canette, A.; Gallopin, M.; Couty, M.; FontaineAupart, M. Natural Rubber-carbon Black Coagulation: Following the Nanostructure Evolution from a Colloidal Suspension to a Composite. Journal of Applied Polymer Science 2020, 50221. https://doi.org/10.1002/app.50221.

(28) Electron Microscopy: Methods and Protocols; Kuo, J., Ed.; Methods in Molecular Biology; Humana Press: Totowa, NJ, 2014; Vol. 1117. https://doi.org/10.1007/978-1-62703-776-1.

(29) Biological Field Emission Scanning Electron Microscopy, First edition.; Fleck, R. A., Humbel, B. M., Eds.; Royal Microscopical Society - John Wiley series; Wiley: Hoboken, NJ, 2019.

(30) Hennig, P.; Denk, W. Point-Spread Functions for Backscattered Imaging in the Scanning Electron Microscope. Journal of Applied Physics 2007, 102 (12), 123101. https://doi.org/10.1063/1.2817591.

(31) Mazzoli, A.; Favoni, O. Particle Size, Size Distribution and Morphological Evaluation of Airborne Dust Particles of Diverse Woods by Scanning Electron Microscopy and Image Processing Program. Powder Technology 2012, 225, 65-71. https://doi.org/10.1016/j.powtec.2012.03.033.

(32) Dazzi, A.; Prater, C. B. AFM-IR: Technology and Applications in Nanoscale Infrared Spectroscopy and Chemical Imaging. Chemical Reviews 2017, 117 (7), 5146-5173. https://doi.org/10.1021/acs.chemrev.6b00448.

(33) Pancani, E.; Mathurin, J.; Bilent, S.; Bernet-Camard, M.-F.; Dazzi, A.; Deniset-Besseau, A.; Gref, R. High-Resolution Label-Free Detection of Biocompatible Polymeric Nanoparticles in Cells. Particle \& Particle Systems Characterization 2018, 35 (3), 1700457. https://doi.org/10.1002/ppsc.201700457.

(34) Wöll, D.; Flors, C. Super-Resolution Fluorescence Imaging for Materials Science. Small Methods 2017, 1 (10), 1700191. https://doi.org/10.1002/smtd.201700191.

(35) Wu, J.; Qu, W.; Huang, G.; Wang, S.; Huang, C.; Liu, H. Super-Resolution Fluorescence Imaging of Spatial Organization of Proteins and Lipids in Natural Rubber. Biomacromolecules 2017, 18 (6), 1705-1712. https://doi.org/10.1021/acs.biomac.6b01827.

(36) Turkowyd, B.; Virant, D.; Endesfelder, U. From Single Molecules to Life: Microscopy at the Nanoscale. Analytical and Bioanalytical Chemistry 2016, 408 (25), 6885-6911. https://doi.org/10.1007/s00216-016-9781-8.

(37) Tokunaga, M.; Imamoto, N.; Sakata-Sogawa, K. Highly Inclined Thin Illumination Enables Clear Single-Molecule Imaging in Cells. Nature Methods 2008, 5 (2), 159-161. https://doi.org/10.1038/nmeth1171.

(38) Kim, D.; Deerinck, T. J.; Sigal, Y. M.; Babcock, H. P.; Ellisman, M. H.; Zhuang, X. Correlative Stochastic Optical Reconstruction Microscopy and Electron Microscopy. PLOS ONE 2015, 10 (4), e0124581. https://doi.org/10.1371/journal.pone.0124581. 
(39) Rahbek-Clemmensen, T.; Lycas, M. D.; Erlendsson, S.; Eriksen, J.; Apuschkin, M.; Vilhardt, F.; Jørgensen, T. N.; Hansen, F. H.; Gether, U. Super-Resolution Microscopy Reveals Functional Organization of Dopamine Transporters into Cholesterol and Neuronal Activity-Dependent Nanodomains. Nat Commun 2017, 8 (1), 740. https://doi.org/10.1038/s41467-017-00790-3.

(40) Hansen, J.-P.; McDonald, I. R. Introduction. In Theory of Simple Liquids; Elsevier, 2013; pp 1-11. https://doi.org/10.1016/B978-0-12-387032-2.00001-5.

(41) Pickering, S. U. CXCVI.-Emulsions. J. Chem. Soc., Trans. 1907, 91 (0), 2001-2021. https://doi.org/10.1039/CT9079102001.

(42) Singh, A. P.; Wi, S. G.; Chung, G. C.; Kim, Y. S.; Kang, H. The Micromorphology and Protein Characterization of Rubber Particles in Ficus Carica, Ficus Benghalensis and Hevea Brasiliensis. Journal of Experimental Botany 2003, 54 (384), 985-992. https://doi.org/10.1093/jxb/erg107.

(43) Rippel, M. M.; Lee, L.-T.; Leite, C. A. P.; Galembeck, F. Skim and Cream Natural Rubber Particles: Colloidal Properties, Coalescence and Film Formation. Journal of Colloid and Interface Science 2003, 268 (2), 330-340. https://doi.org/10.1016/j.jcis.2003.07.046.

(44) Boitte, J.-B.; Hayert, M.; Michon, C. Observation of Wheat Flour Doughs under Mechanical Treatment Using Confocal Microscopy and Classification of Their Microstructures. Journal of Cereal Science 2013, 58 (3), 365-371. https://doi.org/10.1016/j.jcs.2013.07.009.

(45) Dinsmore, H. L.; Smith, D. C. Analysis of Natural and Synthetic Rubber by Infrared Spectroscopy. Anal. Chem. 1948, 20 (1), 11-24. https://doi.org/10.1021/ac60013a004. 
